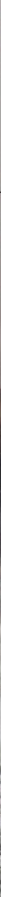

\title{
Precipitaciones intensas en las zonas del este y del sureste peninsulares (Dic-2016 y Mar-2017)
}

\author{
Benito Elvira Montejo \\ Cecilia Marcos Martín \\ Área de Técnicas y Aplicaciones de Predicción (ATAP), AEMET \\ Miguel Ángel Martínez Rubio \\ Unidad de satélites, AEMET \\ JosÉ ÁNGEL NúÑEZ MORA \\ Delegación territorial (DT) en Valencia, AEMET
}

Área de Predicción Operativa (APRO), Agencia Estatal de Meteorología (AEMET)MET

No pretendas apagar con fuego un incendio, ni remediar con agua una inundación.

CONFUCIO

En el área mediterránea se dan a menudo episodios de precipitaciones intensas. Hemos elegido dos episodios de este tipo en el este y sureste de la Península para estudiarlos en detalle en este capítulo, uno en torno al 18 de diciembre de 2016 (examinado desde otros puntos de vista en el capítulo 50 en la página 763 de este volumen) y el otro centrado en el 13 de marzo de 2017. En ambos se registraron precipitaciones muy fuertes, incluso torrenciales. Analizamos el comportamiento de los sistemas de predicción del Centro Europeo de Predicción a Medio Plazo (ECMWF, cap. 19 en la página 289), tanto el modelo de alta resolución ECHRES (sec. 19.2 en la página 291) como el sistema de predicción por conjuntos ECENS (sec. 19.3 en la página 293).

Palabras clave: sistemas de predicción por conjuntos aplicados a la predicción de corto y medio plazo, predicción probabilista, precipitaciones intensas en el este y sureste peninsular diciembre 2016 y marzo 2017. 

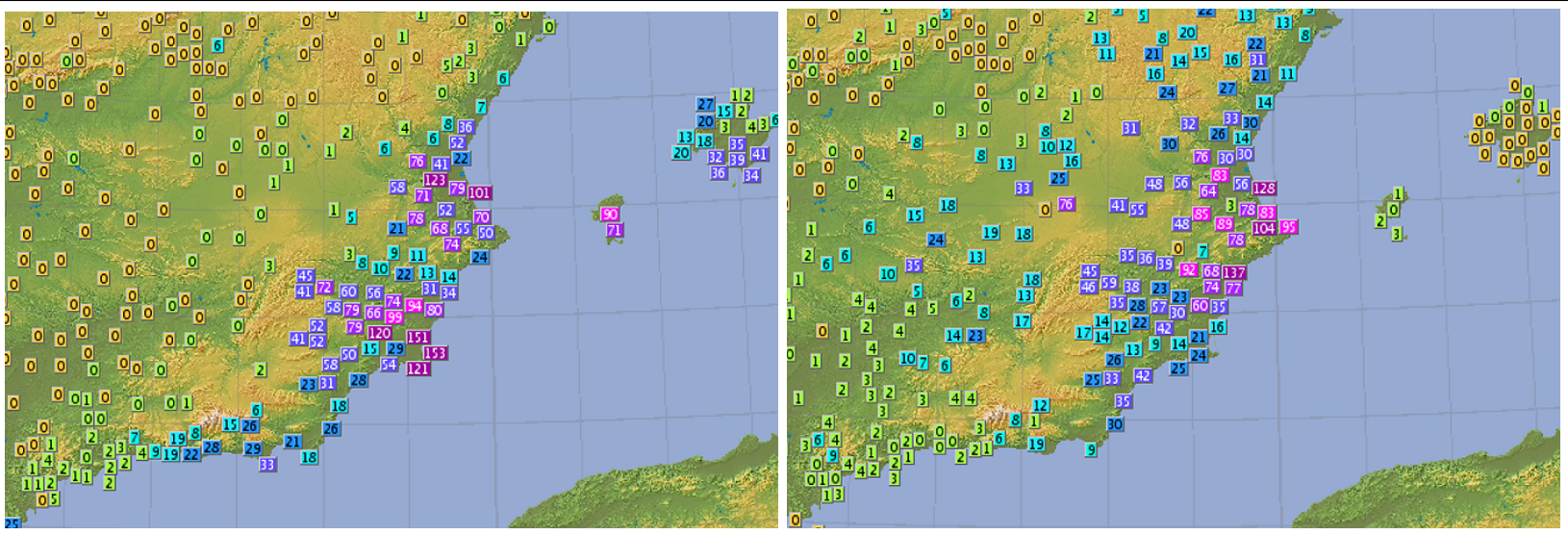

Figura 51.1: Precipitación en 24 horas, 00 a 24 UTC, para el 18-12-2016 (izquierda) y el 13-03-2017 (derecha).

\subsection{Introducción}

En este trabajo analizamos el comportamiento del modelo de alta resolución y del sistema de predicción por conjuntos (SPC) del ECMWF: ECHRES (sec. 19.2 en la página 291) y ECENS (sec. 19.3 en la página 293), respectivamente, en la predicción de precipitaciones intensas en el este y sureste peninsular. Hemos elegido dos episodios, uno en torno al 18 de diciembre de 2016 y el otro centrado en el 13 de marzo de 2017, que a partir de ahora denominaremos A y B, respectivamente. En ambos se registraron precipitaciones muy fuertes, incluso torrenciales (ver Figura 51.1). Para llevar a cabo este estudio se ha seleccionado un periodo de 24 horas (00 a 24 UTC) para cada episodio, coincidente aproximadamente con los días naturales: 18-12-2016 y 13-03-2017.

\subsection{Diagnóstico de los episodios}

\subsubsection{Episodio A del 18-12-2016: caracte- rización sinóptica}

El diagnóstico de niveles medios y altos se caracteriza por una depresión aislada de niveles altos (DANA), con varios centros de vorticidad, V1 y V2, presencia de un núcleo frío de hasta $-26^{\circ} \mathrm{C}$ en $500 \mathrm{hPa}$ y zona difluente sobre el este peninsular y Mediterráneo occidental, Figura 51.2 (izquierda). En niveles bajos, en la imagen IR se observa una muy larga banda nubosa que se ha interpretado como un frente ocluido y que recorre desde el Mediterráneo central hasta el noreste de Baleares, Figura 51.2 (derecha).
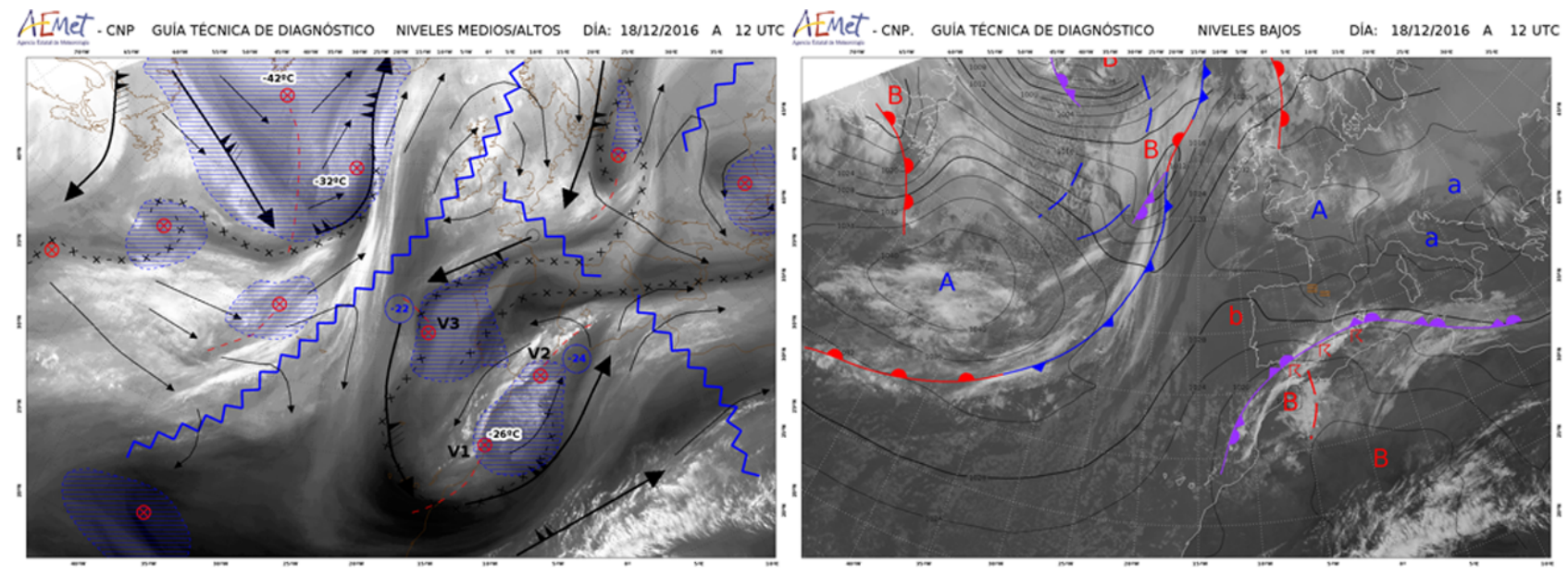

Figura 51.2: Diagnóstico para el día 18-12-2016 a las 12 UTC en niveles medios y altos junto con la imagen de vapor de agua (WV, izquierda, ver capítulo 7 en la página 83) y en niveles bajos junto con la imagen infrarroja (IR, derecha). 

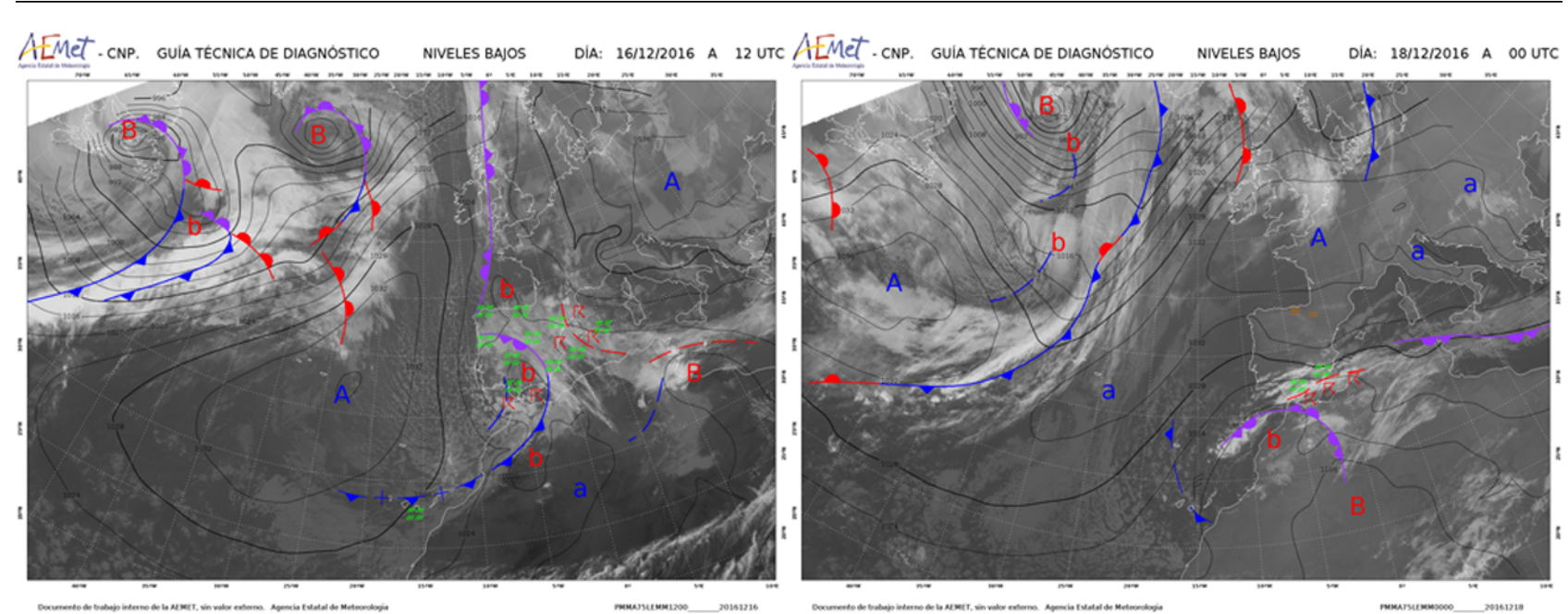

Figura 51.3: Diagnóstico niveles bajos para el día 16-12-2016 a las 12 UTC (izquierda) y para el día 18-12-2016 a las 00 UTC (derecha).

La humedad, según reflejan las imágenes WV (sec. 7.4.3 en la página 92), es alta; y es aportada, por una parte, por un flujo intenso del E, con gran recorrido marítimo, inducido por la presencia de una baja extensa en el norte de África y, por otra, por el viento del SW en niveles medios y altos, asociado a la DANA. Es lo que a veces se denomina chorro de humedad o río atmosférico.

Inicialmente el 16-12-2016 a las 12 UTC, el flujo del $\mathrm{E}$ (de levante) es menos marcado pero en las 36 horas siguientes, la ciclogénesis del golfo de Cádiz y la reorientación del anticiclón europeo, han intensificado significativamente el flujo del E sobre el este y sureste peninsular (ver Figura 51.3).

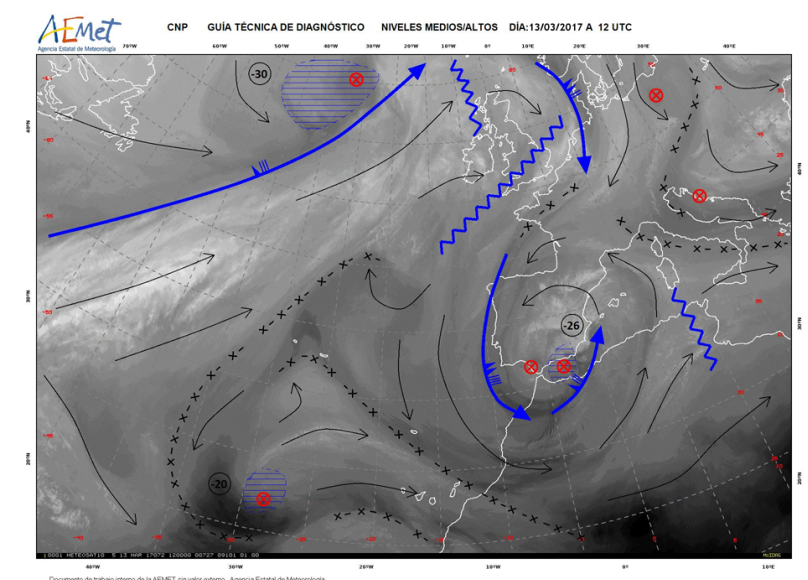

\subsubsection{Episodio B del 13-03-2017: caracte- rización sinóptica}

El diagnóstico de niveles medios y altos se caracteriza por una DANA, con dos centros de vorticidad, presencia de un núcleo frío de hasta $-26^{\circ} \mathrm{C}$ en $500 \mathrm{hPa}$ y zona difluente sobre el este peninsular y Mediterráneo occidental. En superficie, en la imagen IR se observa una banda nubosa al norte de África, que se ha interpretado como un frente frío y una zona nubosa, que cubre la mitad este peninsular, resultado de la ciclogénesis en niveles bajos que progresivamente intensifica el flujo persistente y húmedo del $\mathrm{E}$ y NE sobre la Comunidad Valenciana y Murcia (ver Figura 51.4).

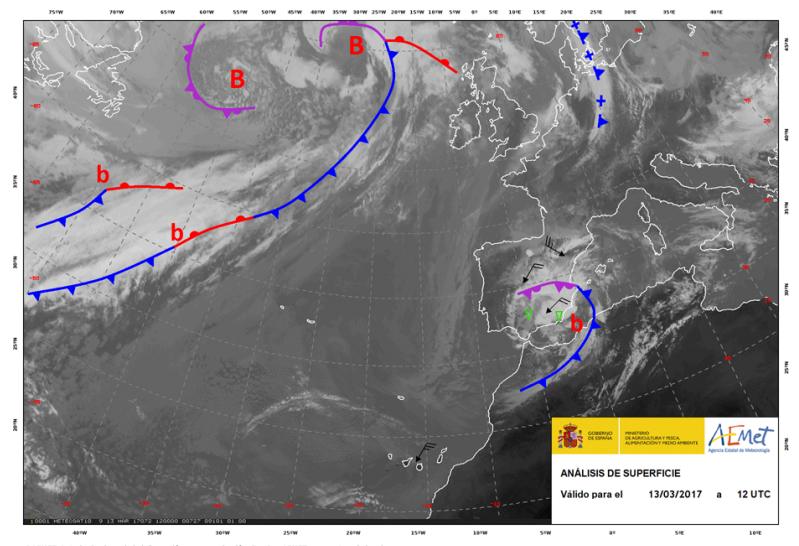

Figura 51.4: Diagnóstico de niveles altos junto con la imagen de vapor de agua (izquierda) y en superficie junto con la imagen infrarroja (derecha) del día 13-03-2017 a las 12 UTC. 


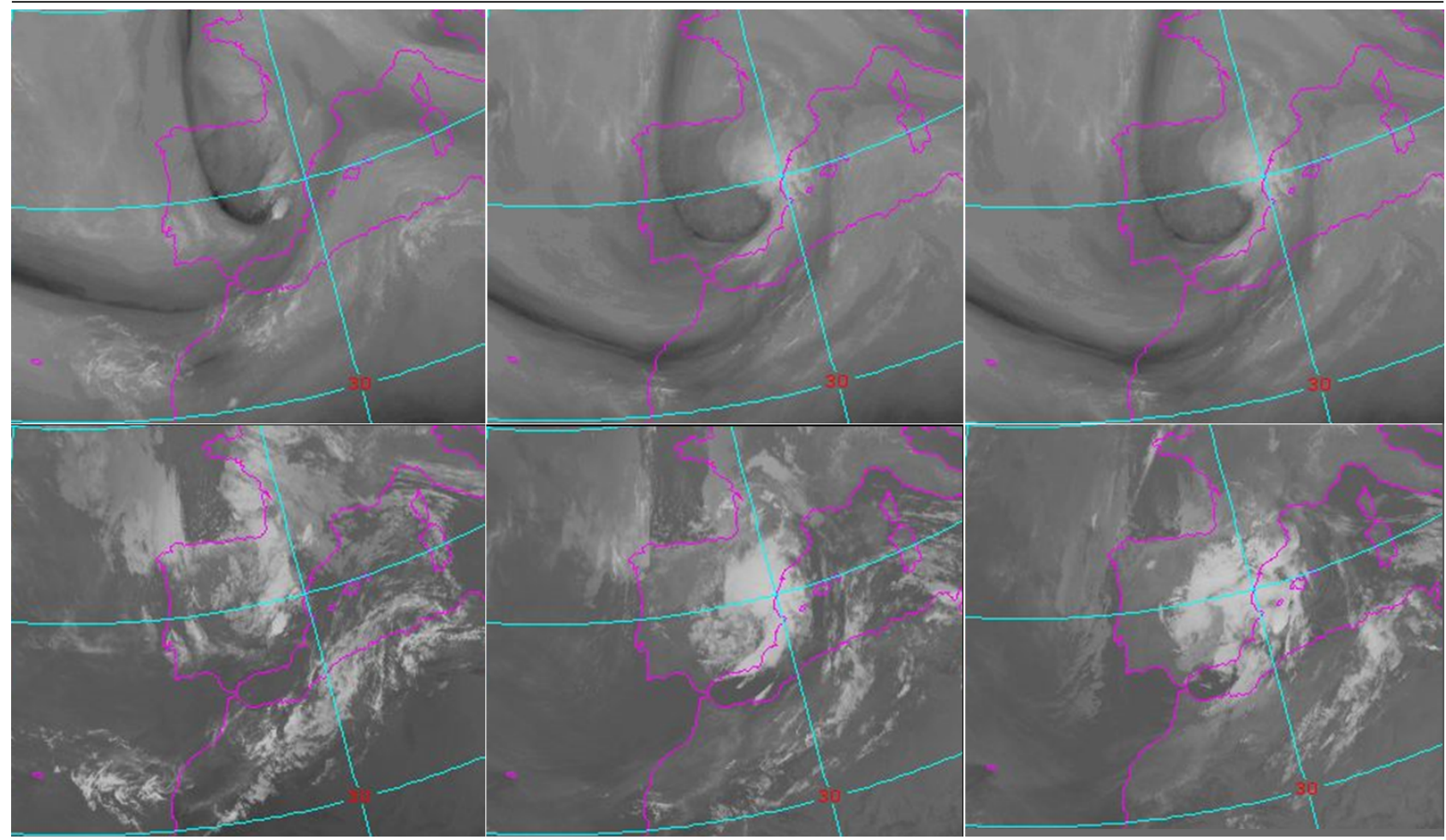

Figura 51.5: Evolución desde el día 12 a las 18 UTC (izquierda) hasta el 13 a las 06 UTC (derecha). Arriba imagen WV. Abajo imagen IR.

En la Figura 51.5 se muestra una evolución previa de las imágenes WV e IR cada 6 horas. En las imágenes WV se observa el proceso de aislamiento de la DANA y como el máximo de viento delantero va adquiriendo mayor protagonismo. Paralelamente tiene lugar una ciclogénesis en niveles bajos que progresivamente intensifica el flujo del E y NE sobre la Comunidad Valenciana y Murcia. Como consecuencia se reorienta y densifica la nubosidad sobre la zona.

\subsubsection{Episodio A del 18-12-2016: estudio mediante teledetección y datos ob- servados}

A últimas horas del día 15 y primeras del día 16 de diciembre, ya se empieza a ver con nitidez la formación de un río de humedad que recorre el sur del mar Mediterráneo en toda su longitud con ayuda del producto MIMIC, que hace estimaciones de agua precipitable total en la columna (TPW) a partir de datos en frecuencias microondas tomados desde satélites polares.
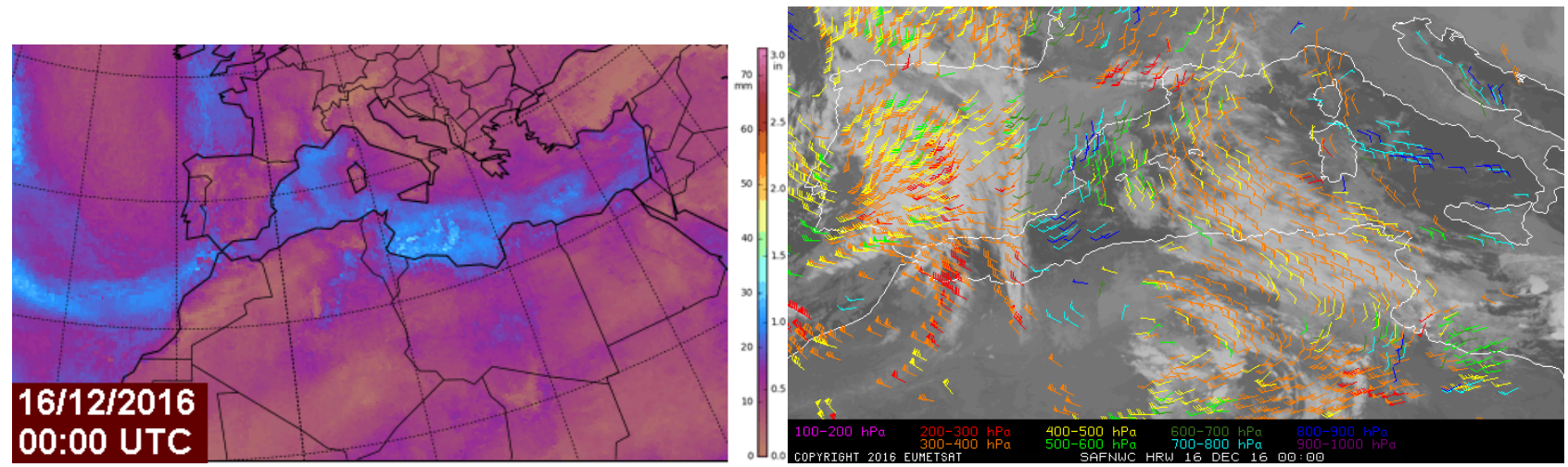

Figura 51.6: Productos MIMIC (@ 2017 Space Science \& Engineering Center; University of Wisconsin - Madison) (izquierda) y HRW (NWCSAF @ 2016 EUMETSAT) (derecha) ambos a las 00 UTC del día 16-12-2016 
Complementando esta información tenemos el producto HRW (High Resolution Winds), desarrollado dentro del proyecto NWCSAF de EUMETSAT, que estima la intensidad y dirección del viento basándose en el movimiento de las estructuras nubosas y de humedad detectadas desde satélite geoestacionario. Dicho producto nos muestra un flujo del SE que transporta la humedad hacia el Levante peninsular. (Ver Figura 51.6 en la página anterior). Con esta información ya se puede intuir un probable episodio de lluvias, más o menos intensas, en esta zona. En este momento, la posible evolución del evento habría que contrastarla con la previsión del modelo numérico.

A lo largo del día 16 dicho río de humedad sigue tomando forma e intensificándose. A primeras horas del día 17 el eje del río de humedad impacta contra las costas de Valencia y empieza un recorrido hacia el sur de la península ibérica hasta alcanzar las costas de Almería al final del día, dejando precipitaciones importantes a lo largo de su recorrido. El día 18 el eje del río de humedad hace un recorrido en sentido inverso, es decir, hacia el norte (Figura 51.7). A la vez que ocurre esto vemos en el producto HRW como los vientos giran a $\mathrm{E}$ y se intensifican (Figura 51.8). Esto hace que aumente la formación de precipitación en la costa con la formación de nuevas tormentas.

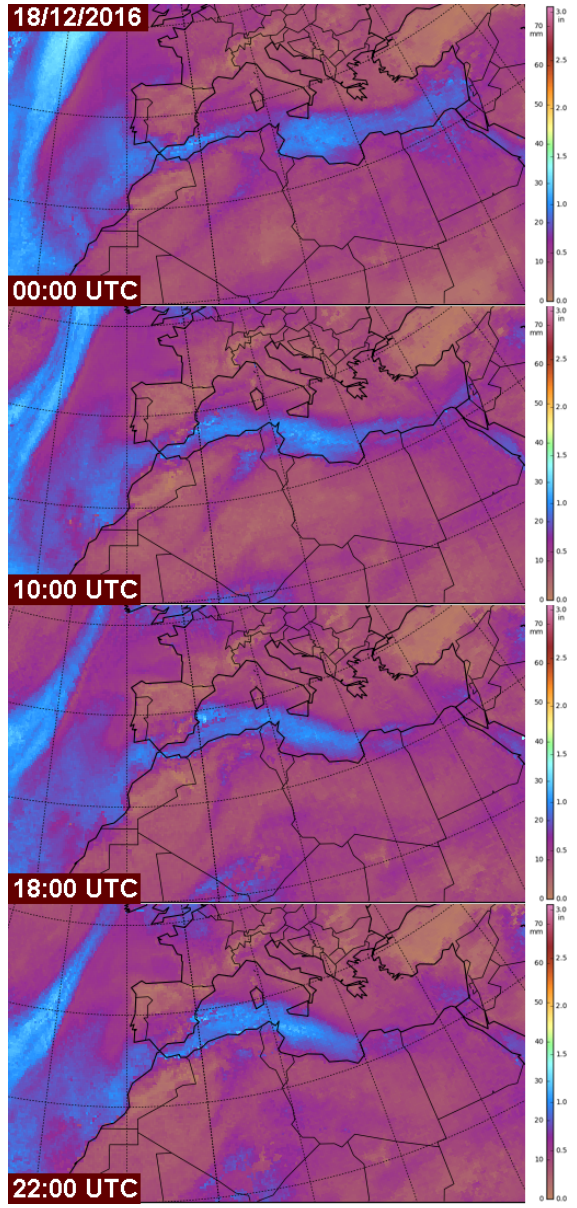

Figura 51.7: Evolución del producto MIMIC (@ 2017 Space Science \& Engineering Center; University of Wisconsin - Madison) a lo largo del día 18-12-2016.

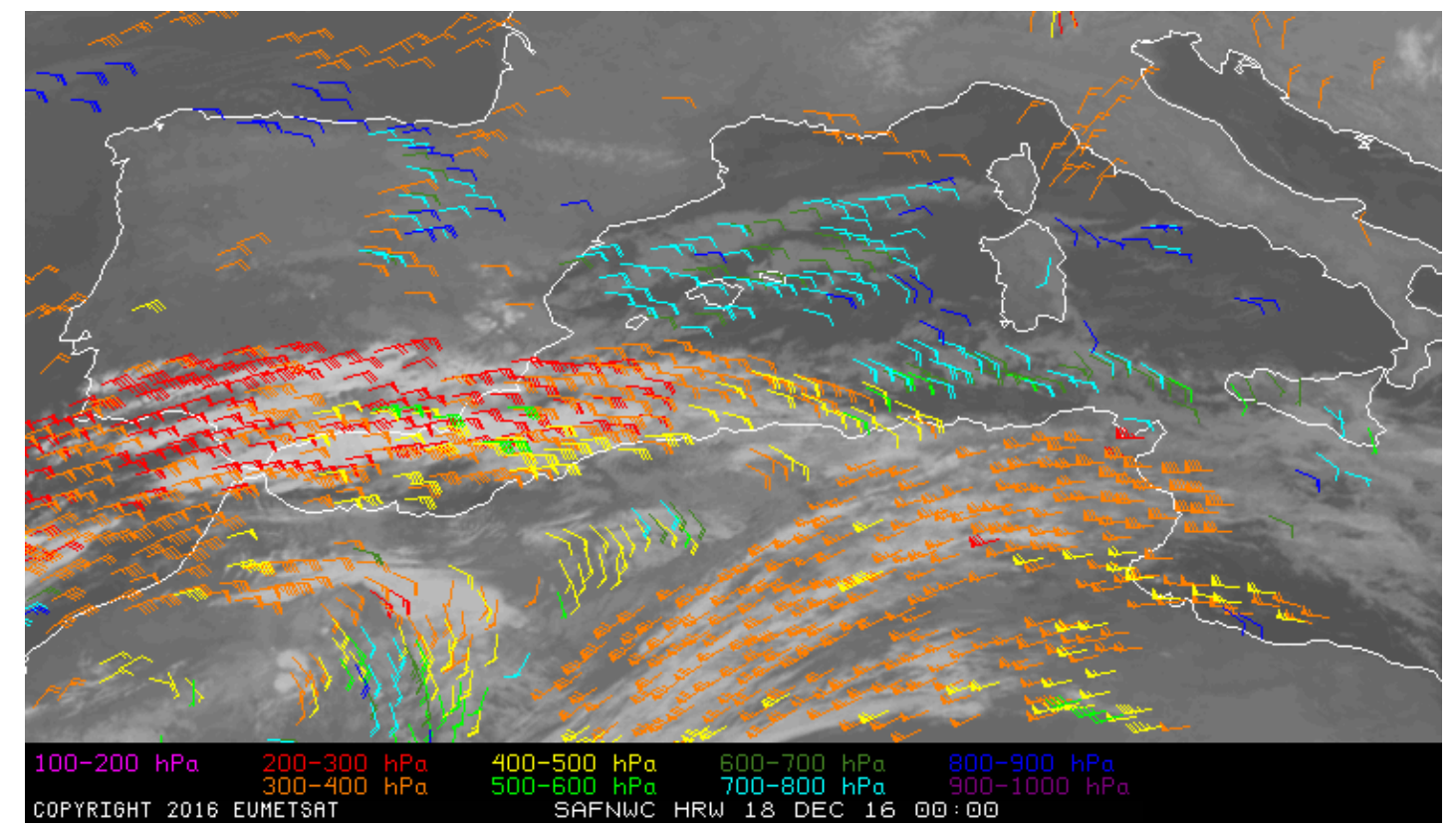

Figura 51.8: Producto HRW (NWCSAF @ 2016 EUMETSAT) a las 00 UTC del día 18-12-2016 
Los efectos en cuanto a precipitación de estas altas cantidades de humedad impactando sobre las costas del sur y Levante español se pueden monitorizar casi en tiempo real gracias a las herramientas de teledetección. En las Figuras 51.9, 51.10 y 51.11 en la página siguiente podemos ver una composición de imágenes con las reflectividades del mosaico nacional de la red de radares de Agencia Estatal de Meteorología (AEMET) (ver capítulo sobre radar), a la izquierda y el producto CRR (ver capítulo sobre satélites 7 en la página 83), arriba a la derecha y las mediciones de precipitación de algunas estaciones de la red de observación de AEMET, abajo a la derecha. En la Figura 51.9, que muestra la situación sobre las 00:50 UTC del día 18, se puede ver una banda de precipitación que cubre la costa sureste peninsular dejando altas cantidades de precipitación en las provincias de Málaga, Granada y Almería. Un ejemplo de la evolución horaria de la misma se presenta para la estación de Almería-Aeropuerto.
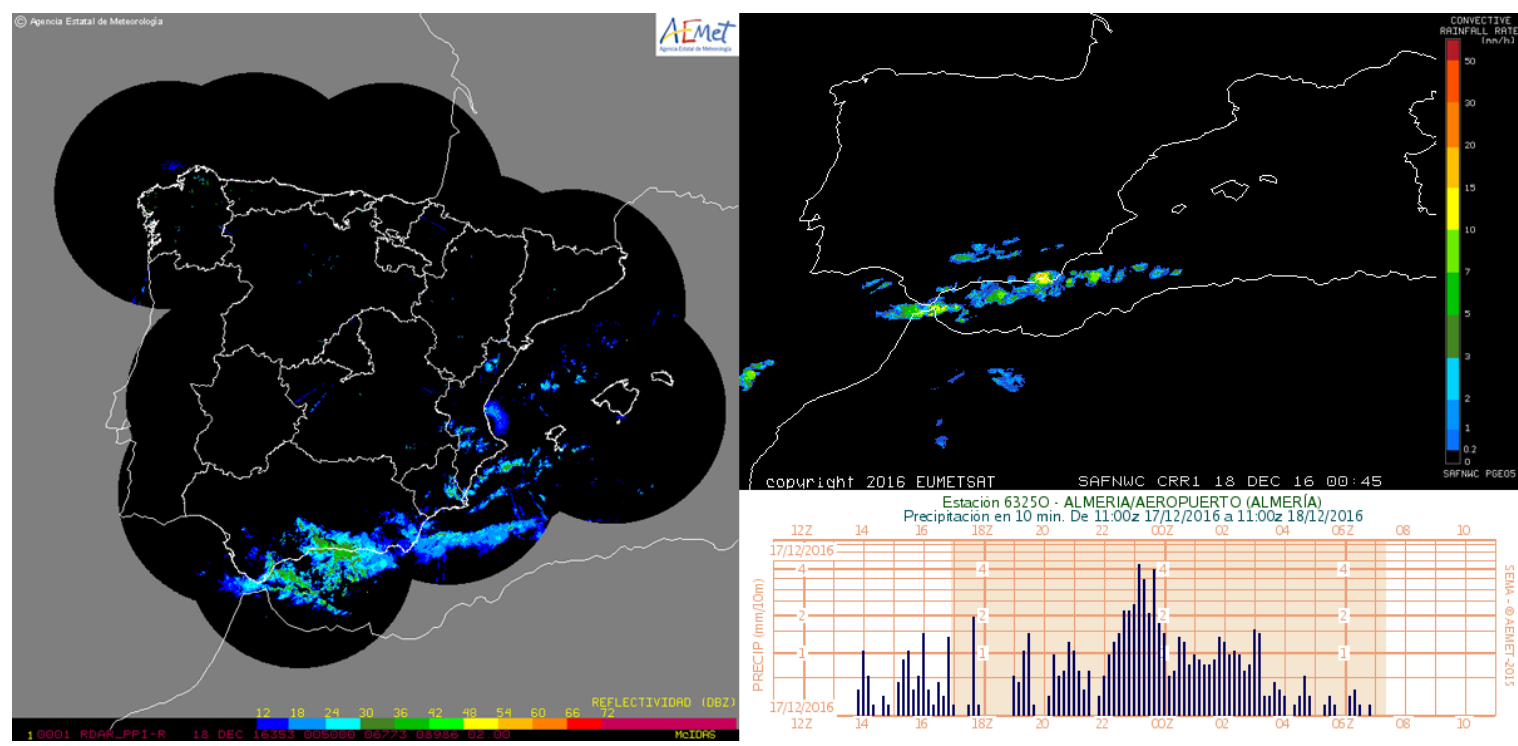

Figura 51.9: Mosaico de la red de radares de AEMET (izquierda) a las 00:50 UTC del día 18. Producto CRR (NWCSAF ( 2016 EUMETSAT) (derecha arriba) a las 00:45 UTC. Registro de precipitaciones en la estación Almería/Aeropuerto desde las 11:00 UTC del día 17 a las 11:00 UTC del día 18.
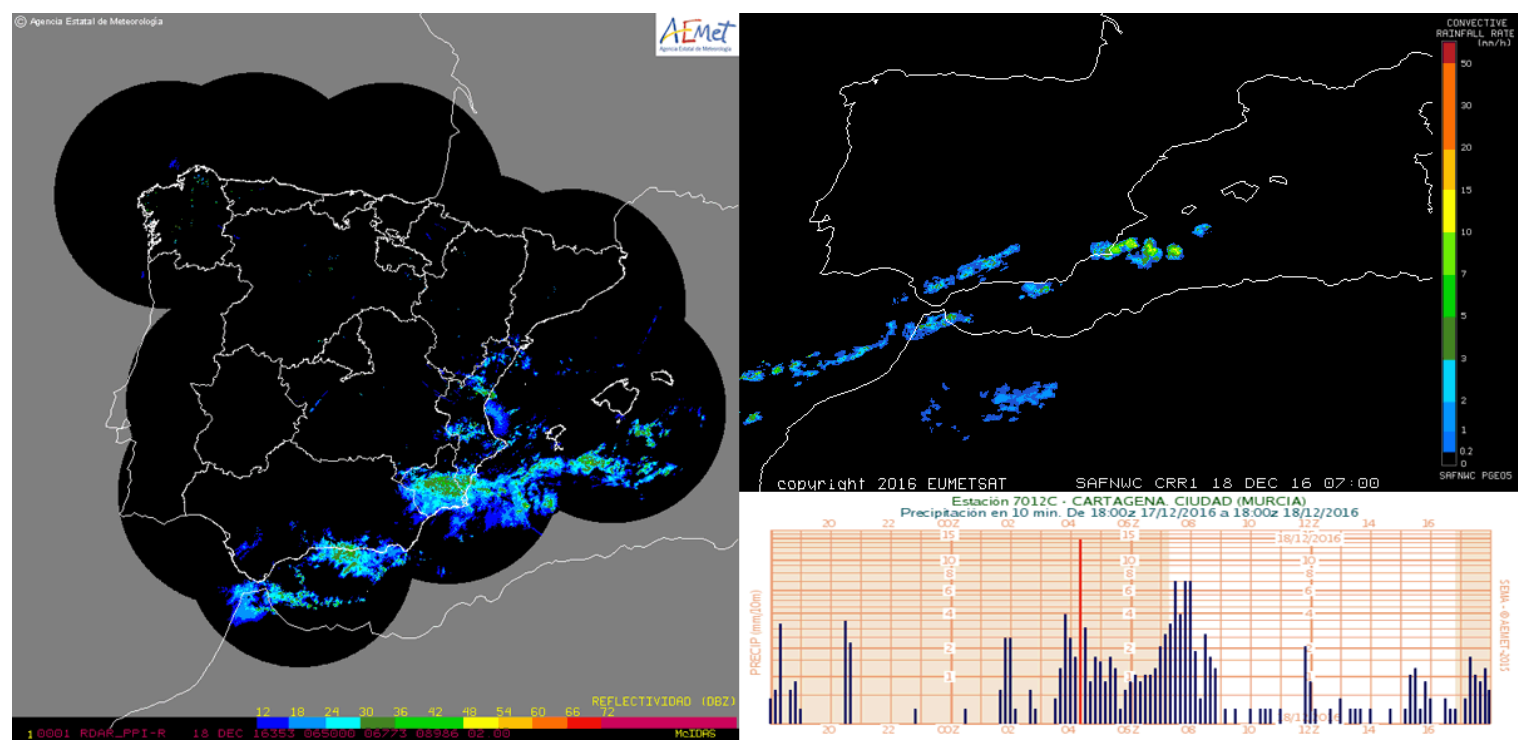

Figura 51.10: Mosaico de la red de radares de AEMET (izquierda) a las 06:50 UTC del día 18. Producto CRR (NWCSAF @ 2016 EUMETSAT) (derecha arriba) a las 07:00 UTC. Registro de precipitaciones en la estación Cartagena Ciudad desde las 18:00 UTC del día 17 a las 18:00 UTC del día 18. 
Seis horas más tarde, en la Figura 51.10 en la página anterior, se puede ver como la banda de precipitación se ha desplazado hacia el norte, tal como se vio en el producto de agua precipitable MIMIC, y se encuentra posicionada a la altura de Murcia. A esas horas se están recogiendo en la estación de Cartagena del orden de $7 \mathrm{~mm}$ en 10 minutos. Trece horas más tarde
(Figura 51.11), la banda de precipitación ya se encuentra a la altura de Valencia y las islas de Ibiza y Mallorca. Alrededor de esa hora, la estación de Oliva registra precipitaciones de más de $15 \mathrm{~mm}$ en $10 \mathrm{minu}-$ tos. La Figura 51.12 muestra las descargas eléctricas producidas durante el episodio.
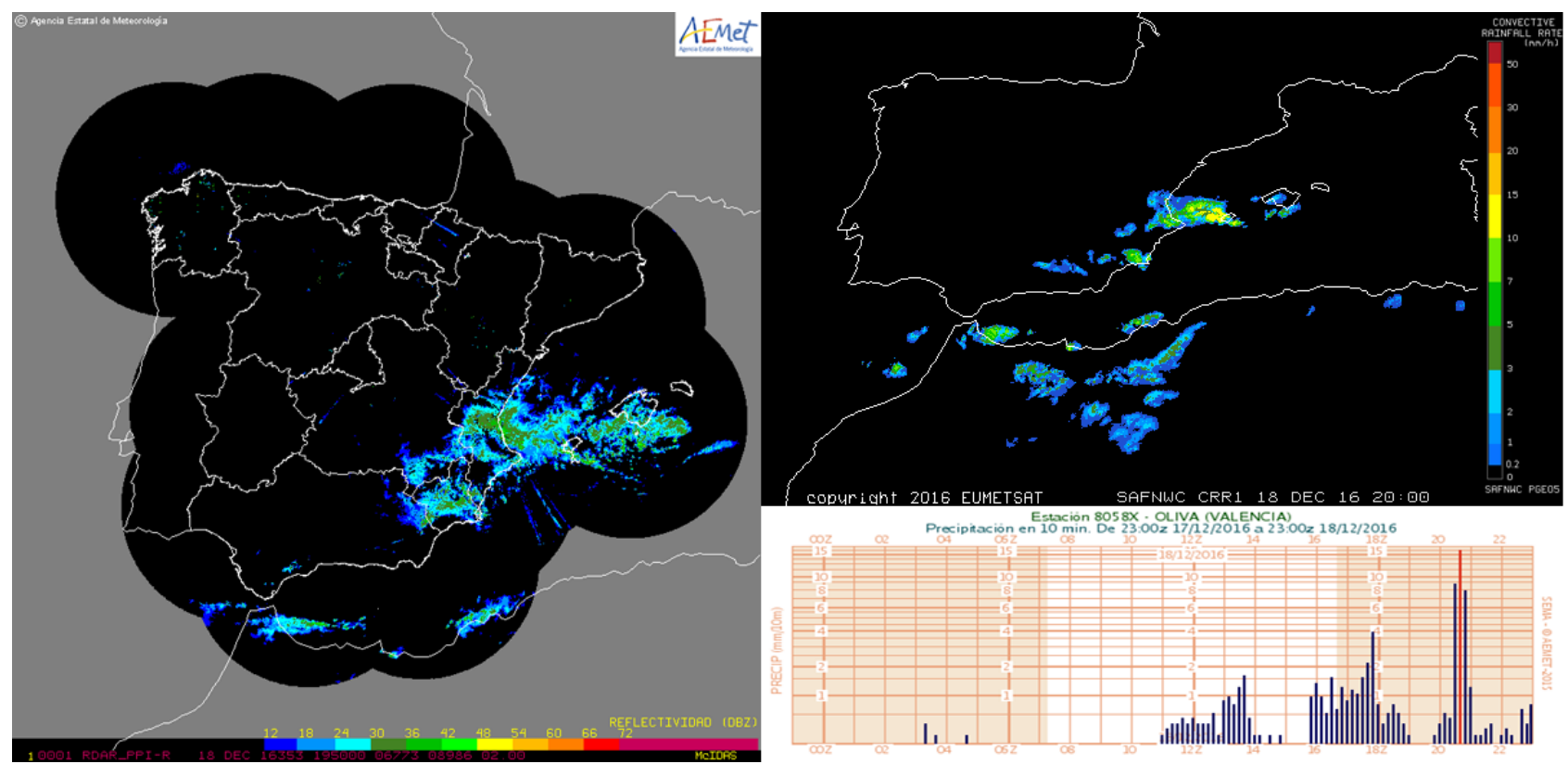

Figura 51.11: Mosaico de la red de radares de AEMET (izquierda) a las 19:50 UTC del día 18. Producto CRR (NWCSAF (C) 2016 EUMETSAT) (derecha arriba) a las 20:00 UTC. Registro de precipitaciones en la estación Cartagena Ciudad desde las 23:00 UTC del día 17 a las 23:00 UTC del día 18.

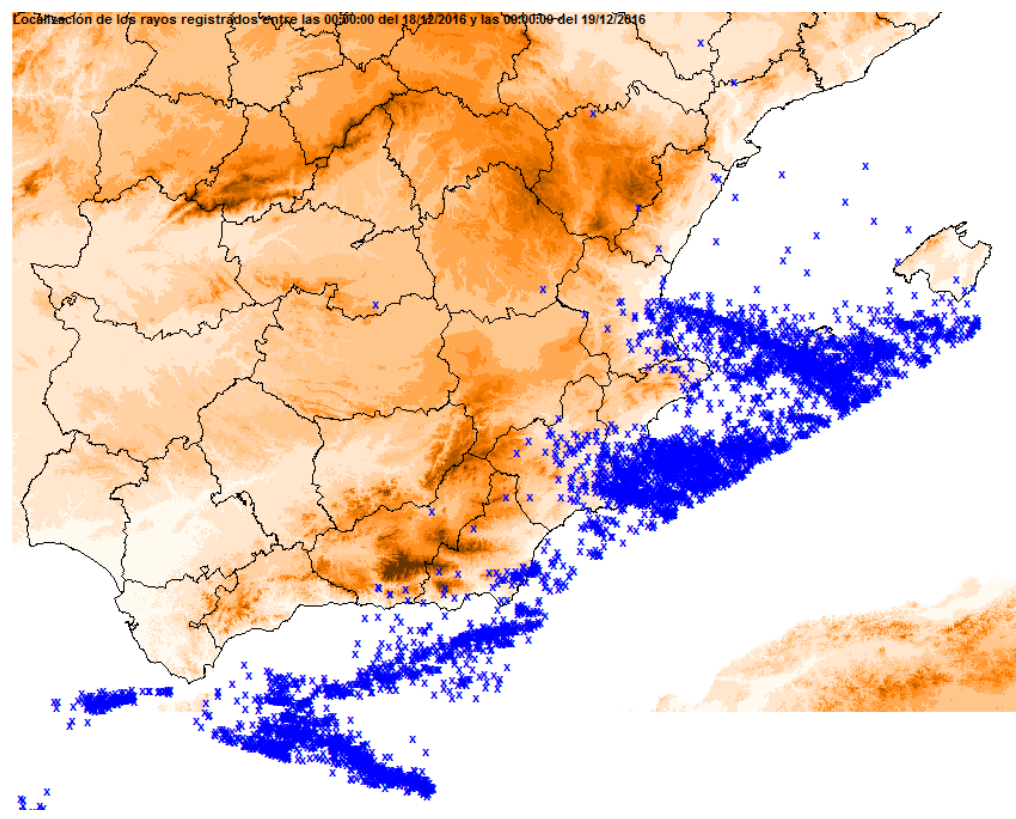

Figura 51.12: Descargas eléctricas registradas por la red de rayos de AEMET durante el día 18/12/2016 


\subsubsection{Episodio B del 13-03-2017: estudio mediante teledetección y datos ob- servados}

Tanto el radar como el producto CRR ya detectan precipitación cerca de la zona de estudio sobre las 18:00 UTC del día 12 de marzo (Figura 51.13). Dicha precipitación se encuentra en el interior peninsular, sobre Cuenca y Albacete aproximadamente y viaja en dirección este hacia Valencia, donde llega sobre las 19:30 UTC debido al movimiento de la baja. Simultáneamente el producto RDT detecta las tormentas en la misma zona desplazándose de manera similar a como lo hace la precipitación en el CRR (Figura 51.14).

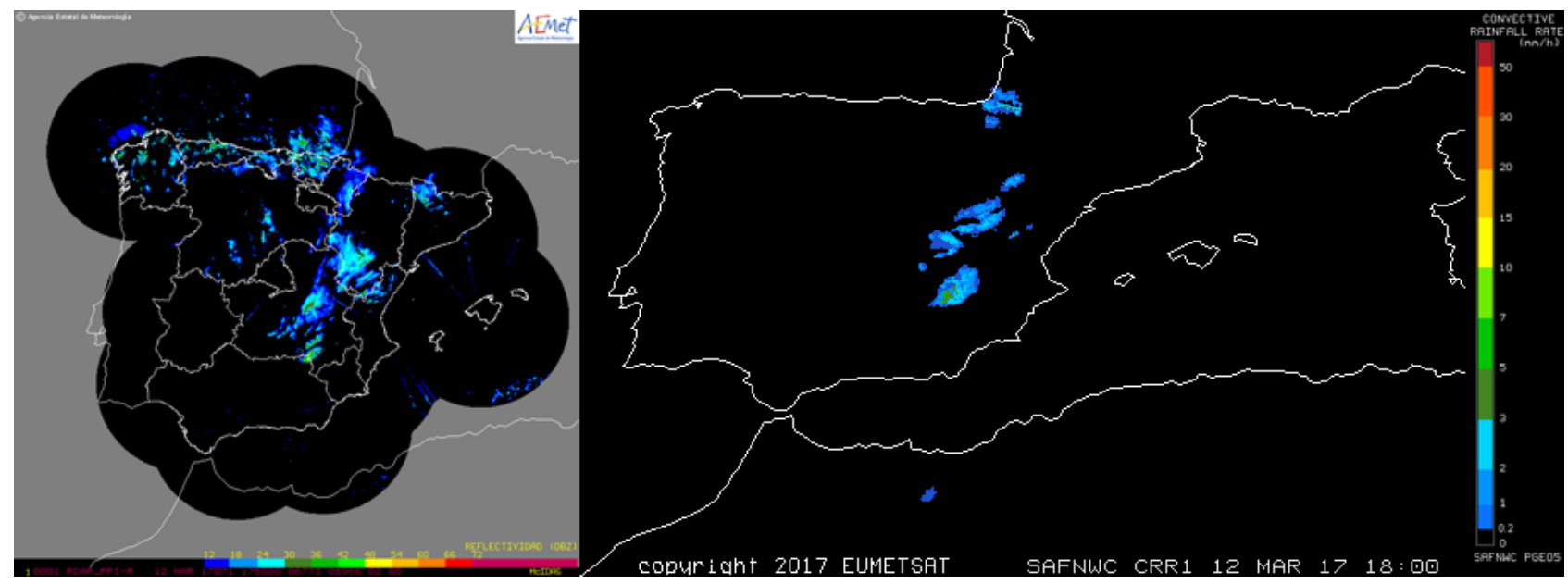

Figura 51.13: Campos de precipitación según el mosaico de la red de radares de AEMET a las 17:50 UTC (izquierda) y según el producto CRR (NWCSAF @ 2016 EUMETSAT) a las 18:00 UTC (derecha) del día 12-03-2017.

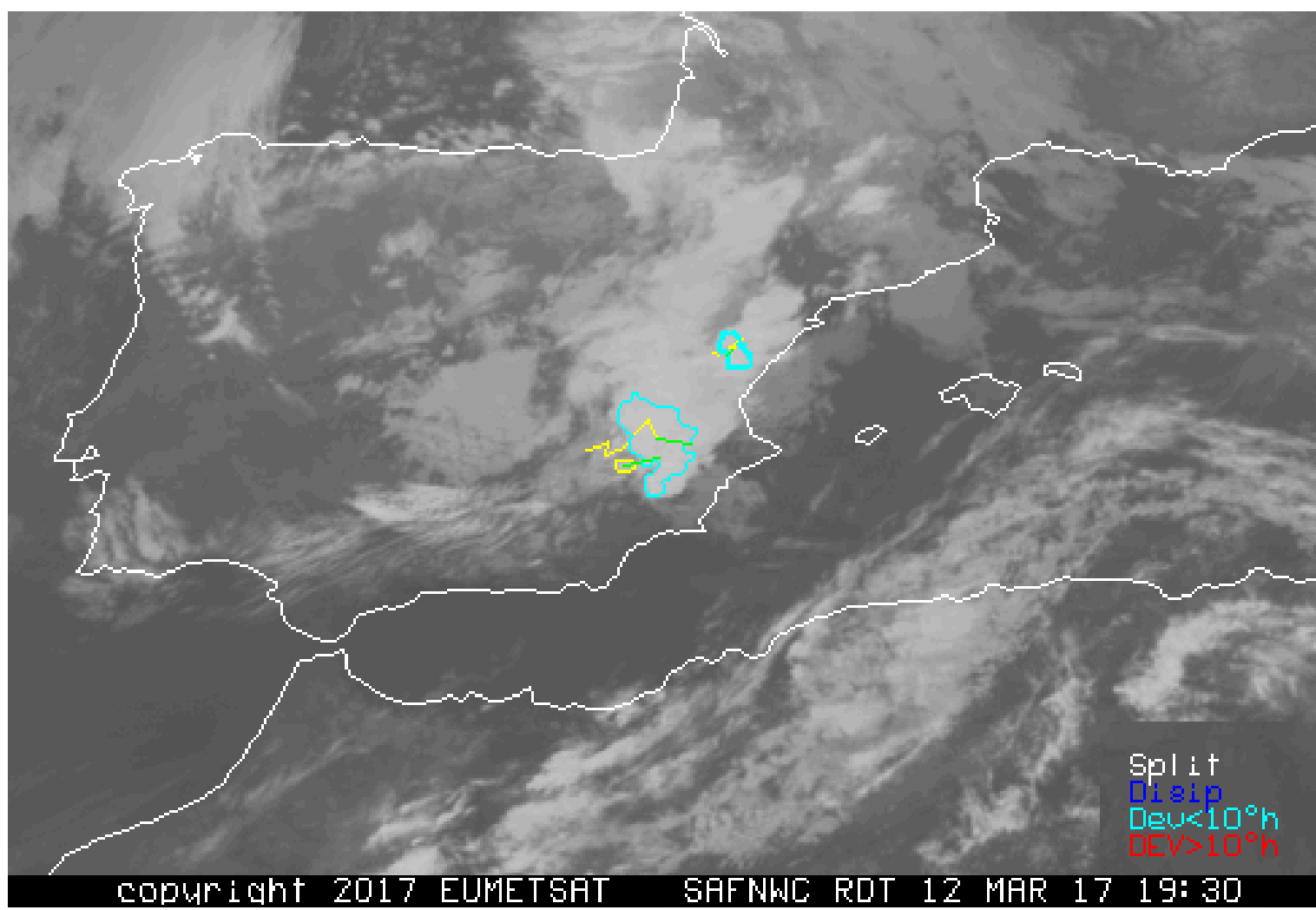

Figura 51.14: Detección de tormentas según el producto RDT (NWCSAF () 2016 EUMETSAT) a las 19:30 UTC del día 12-03-2017 

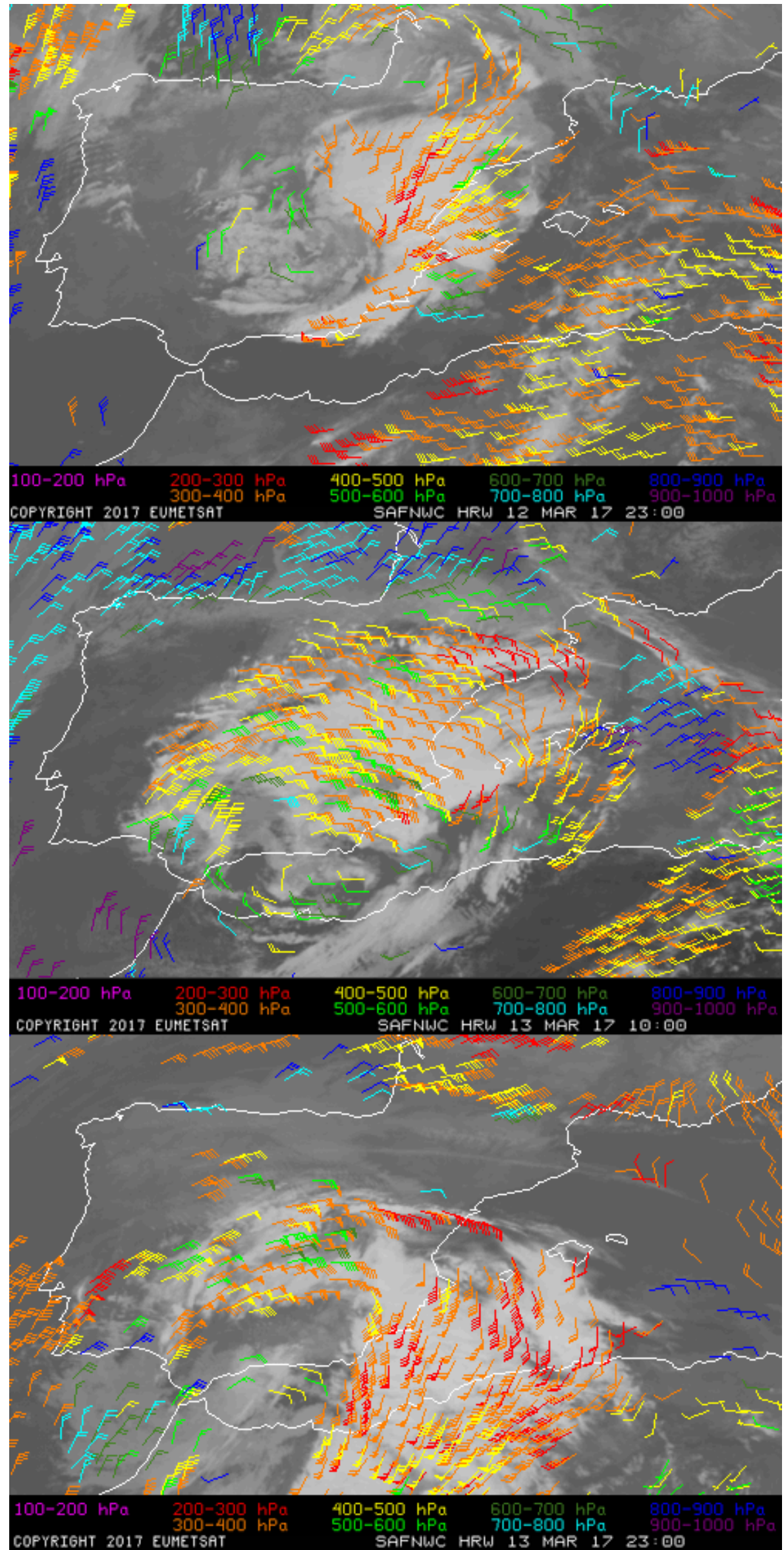

Figura 51.15: Evolución del viento según el producto HRW (NWCSAF @ 2016 EUMETSAT) de las 23:00 UTC del día 12-03-2017 y a las 10:00 y 23:00 UTC del 13-03-217 
En el producto HRW vemos cómo el flujo, que a últimas horas del día 12 de marzo es del W, durante el día 13 de marzo cambia a $\mathrm{E}$ y luego a $\mathrm{S}$, perfilando el movimiento de la baja (Figura 51.15 en la página anterior).

La zona más afectada por este temporal y donde mayores acumulaciones de precipitación se recogieron fue la ciudad de Alicante y alrededores. En concreto se recogieron 112.2 litros en la estación de Alicante en el día 13 (día pluviométrico), siendo este el máximo de precipitación recogido en dicha estación para un día de un mes de marzo de toda la serie. La Figura 51.16 muestra la evolución de la precipitación en la estación de Alicante. La Figura 51.17 muestra cómo detecta la precipitación el producto CRR en torno a las horas de máxima intensidad.

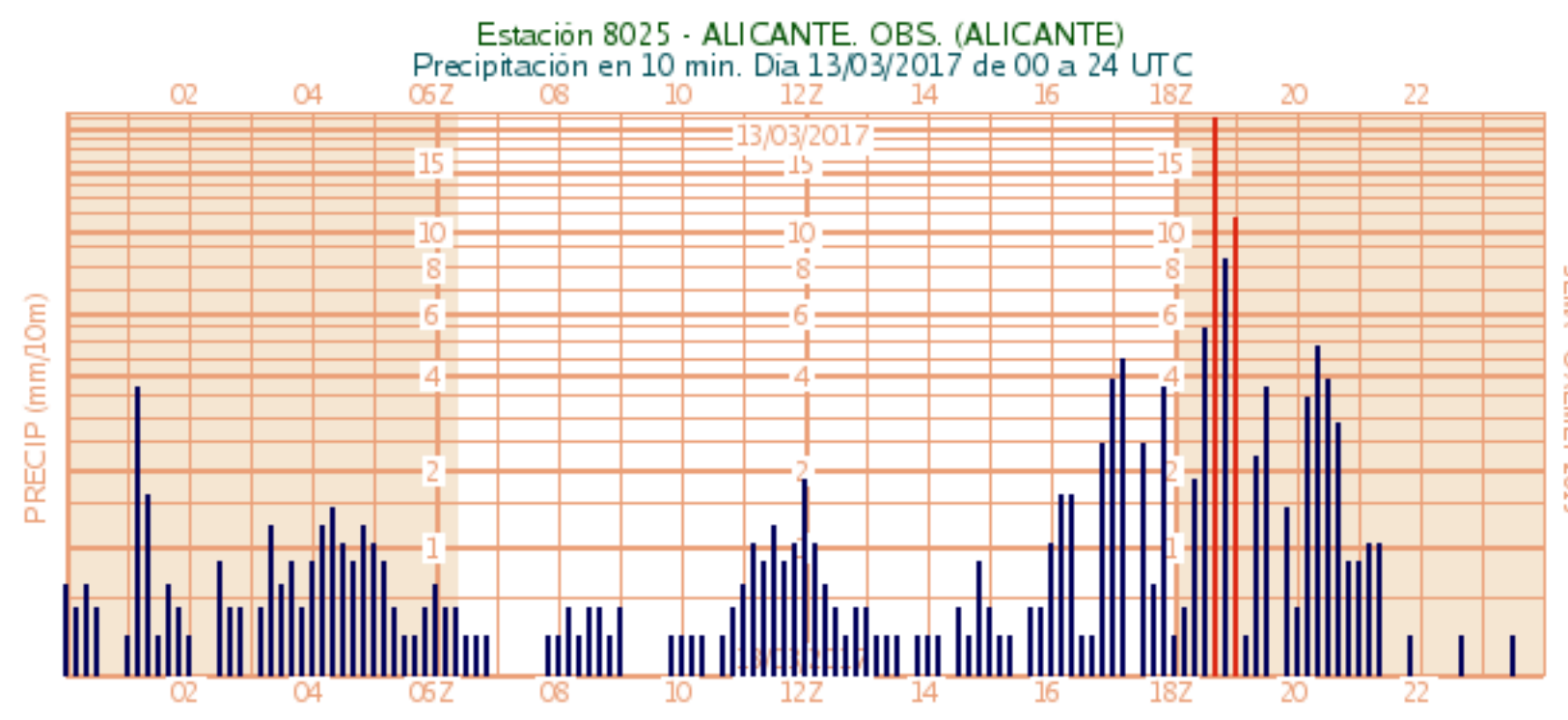

Figura 51.16: Precipitación en 10 minutos recogida en la estación del Observatorio de Alicante a lo largo del día 13-03-2017

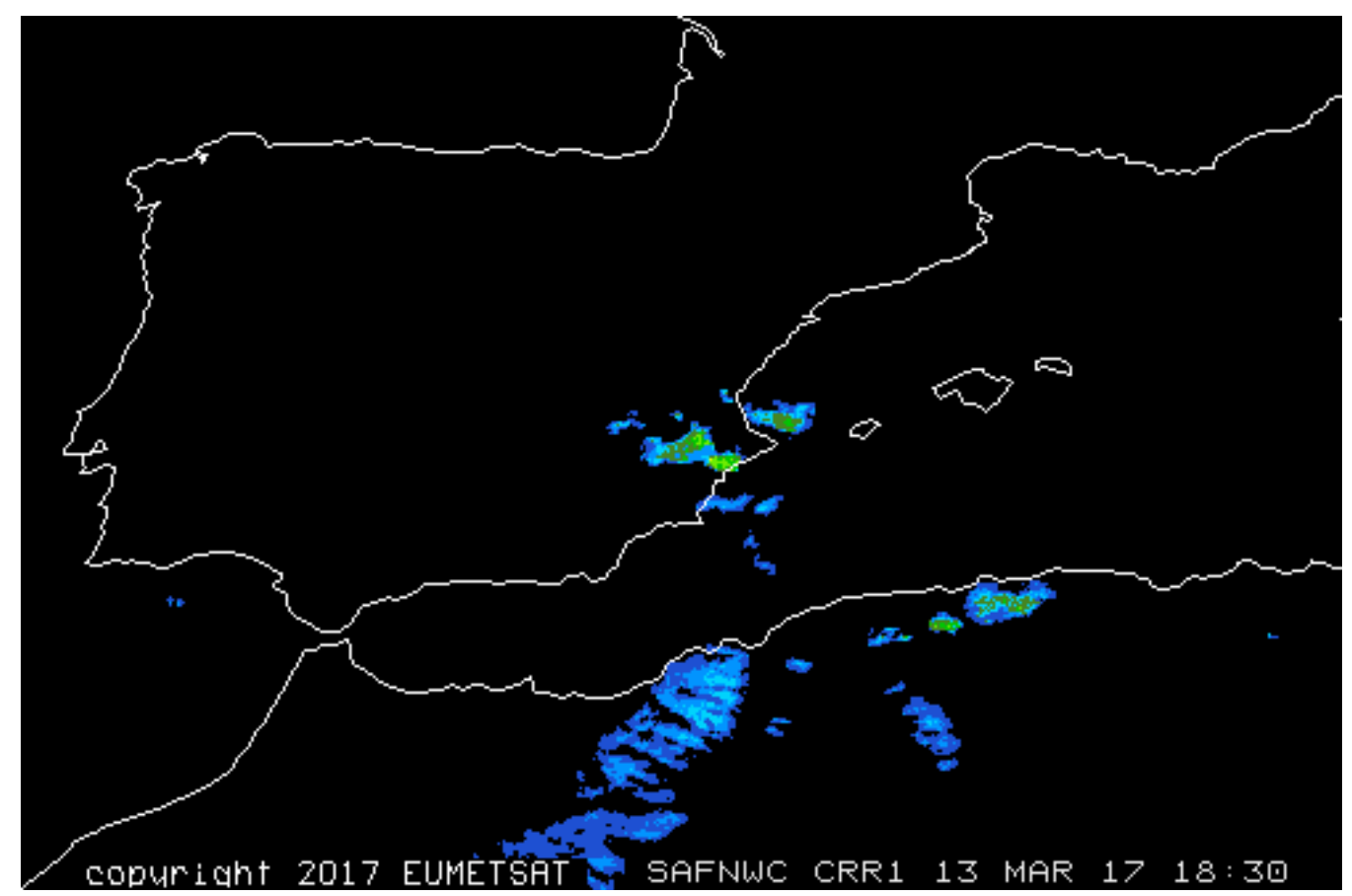

Figura 51.17: Estimación de precipitación instantánea del producto CRR (NWCSAF @ 2016 EUMETSAT) el 13-03-2017 a las 18:30 UTC 


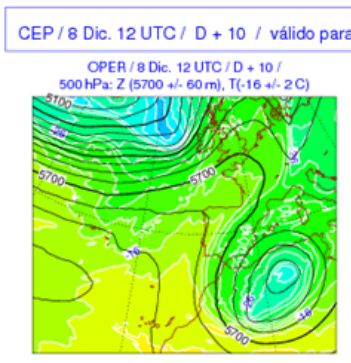

OPEA / 8 Dic, 12 UTC $/ D+10 /$

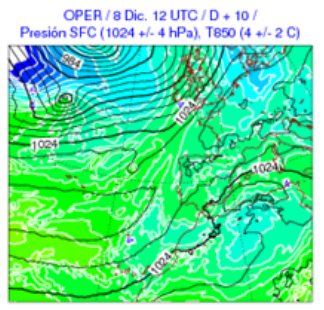

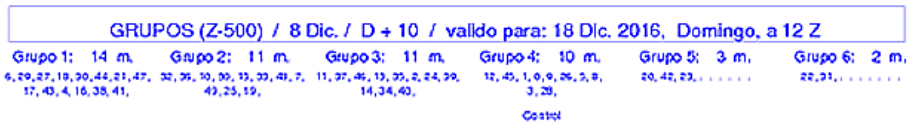

$\cos 1 \mathrm{~s}$

$500 \mathrm{hPa}: Z(5700+1.60 \mathrm{~m}), \mathrm{T}(-16+1.2 \mathrm{C})$
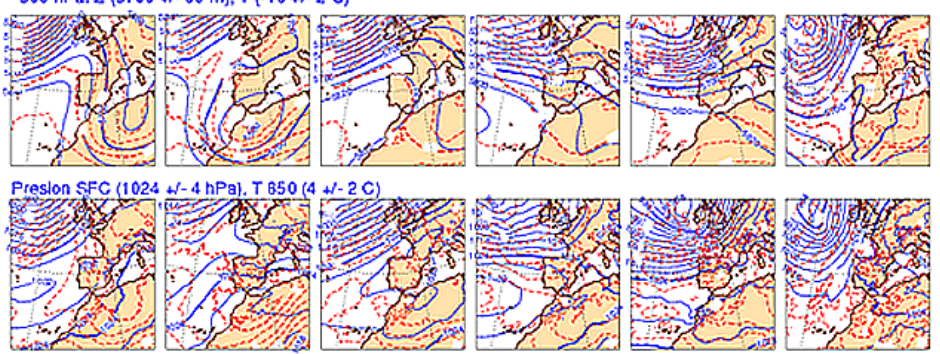

Prob. de pace. 101. (0.12) superior a 1 mm para cada grupo: (int- 10. 40.70.90\%)

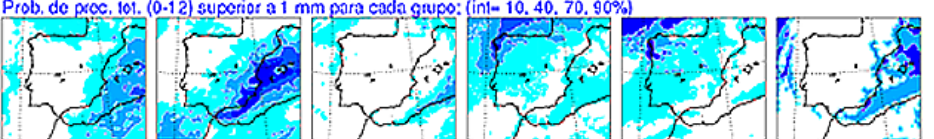

Figura 51.18: ECHRES y Control para D+10 (izquierda). Grupos para D+10 (derecha).

\subsection{Comportamiento ECMWF: ECHRES Y ECENS}

En este apartado queremos responder a la pregunta: ¿con qué antelación se puede predecir este tipo de situaciones meteorológicas? En los últimos 17 años, periodo en el que se está utilizando el ECENS de forma operativa en AEMET, los modelos han mejorado vertiginosamente $y$, en particular, el ECENS [1]. De forma que no es descabellado analizar la predecibilidad de estas situaciones desde unos 10 días antes. En primer lugar, realizaremos un estudio subjetivo, analizando la consistencia de ECHRES y del ECENS, y los diferentes escenarios proporcionados por el ECENS. Posteriormente nos centraremos en los mapas de probabilidad de precipitación y campos específicos para fenómenos extremos, tales como el EFI (sec. 27.7.2 en la página 420) y el SOT (sec. 27.7.3 en la página 421).

\subsubsection{Episodio A del 18-12-2016: escena- rios}

El modelo ECHRES muestra (Figura 51.18) a D+10 una DANA y en niveles bajos un flujo húmedo del este sobre el área mediterránea; lo que contrasta con la predicción de Control que prevé la circulación del $\mathrm{W}$ en todos los niveles.

En los grupos del ECENS aparecen tres escenarios: (a) Grupos 1 y 2; circulación meridiana con baja en el entorno del mediterráneo occidental o norte de África; realmente el grupo 2 es el único que se parece a ECHRES (22\%), (b) Grupos 4 y 5; circulación zonal (30\%) y (c) Grupo 3; dorsal (20\%); el grupo 6, muy minoritario, no está muy definido sobre la Península. En este caso de fuerte discrepancia entre ECHRES y Control se complica la labor del predictor pues el ECENS posiblemente subestime el escenario de ECHRES.

Durante los días siguientes, con las nuevas pasadas disponibles, se observa un gradual aumento de la probabilidad asociada a los escenarios susceptibles de producir precipitaciones intensas en la costa mediterránea, hasta el día 11 a las 12 UTC y días sucesivos, cuando TODOS los escenarios pueden producir lluvias intensas. En la Tabla 51.1 se muestra este incremento:

\begin{tabular}{|l|c|c|c|c|c|c|c|c|c|}
\hline \hline Pasada: & $\begin{array}{c}8 / 12 / 2016 \\
\text { a } 12 \text { UTC }\end{array}$ & $\begin{array}{c}9 / 12 / 2016 \\
\text { a 00 UTC }\end{array}$ & $\begin{array}{c}9 / 12 / 2016 \\
\text { a } 12 \text { UTC }\end{array}$ & $\begin{array}{c}10 / 12 / 2016 \\
\text { a 00 UTC }\end{array}$ & $\begin{array}{c}10 / 12 / 2016 \\
\text { a 12 UTC }\end{array}$ & $\begin{array}{c}11 / 12 / 2016 \\
\text { a 00 UTC }\end{array}$ & $\begin{array}{c}11 / 12 / 2016 \\
\text { a 12 UTC }\end{array}$ & $\begin{array}{c}12 / 12 / 2016 \\
\text { a 00 UTC }\end{array}$ & $\begin{array}{c}12 / 12 / 2016 \\
\text { a 12 UTC }\end{array}$ \\
\hline \hline Probabilidad: & $22 \%$ & $48 \%$ & $52 \%$ & $\begin{array}{c}\text { Dato no } \\
\text { disponible }\end{array}$ & $72 \%$ & $78 \%$ & $100 \%$ & $100 \%$ & $100 \%$ \\
\hline \hline
\end{tabular}

Tabla 51.1: Evolución de las probabilidades de escenarios susceptibles de producir precipitaciones intensas en la costa mediterránea. 


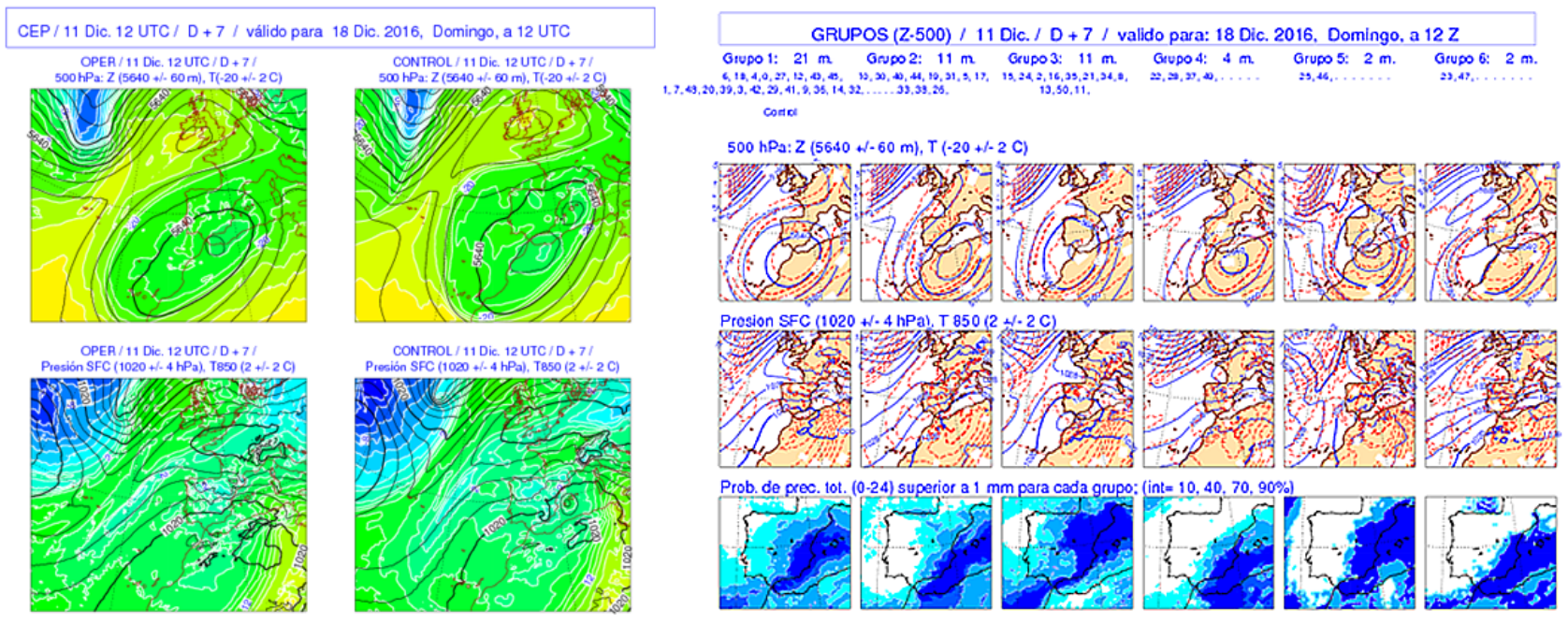

Figura 51.19: ECHRES y Control para D+7 (izquierda). Grupos para D+7 (derecha).

De la tabla se pueden extraer dos rasgos del ECENS para esta situación: 1 . Consistencia y 2. Aumento gradual de las probabilidades. Realmente es un caso de comportamiento ideal de ECENS: desde 10 días antes, con probabilidades crecientes, aparece el escenario de las lluvias fuertes hasta 7 días antes, cuando dicha probabilidad es máxima. No obstante los diferentes grupos no son idénticos (Figura 51.19), se diferencian principalmente en el flujo de niveles bajos que focalizará la convección intensa. De momento toda la costa mediterránea, desde Alborán hasta Cataluña, puede verse afectada.

A partir del día 15 (D+3) y día 16 (D+2) ECHRES y ECENS (Figura 51.20) recuperan la consistencia, focalizando en el este y sureste peninsular las lluvias fuertes.

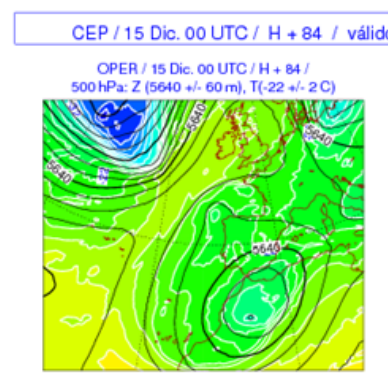

OPER/ 15 Dic. 00 UTC $/ \mathrm{H}+84$

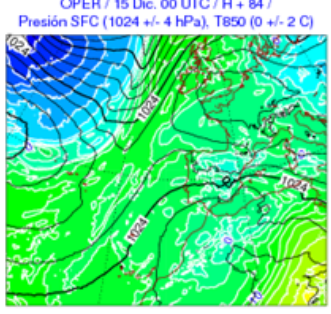

OPER / 15 Dic. 00 UTC $/ \mathrm{H}+8 \mathrm{BA} /$

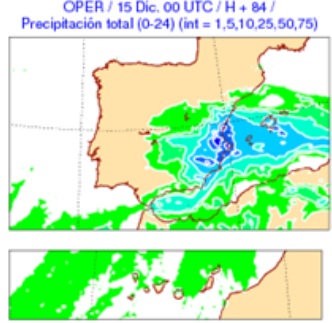

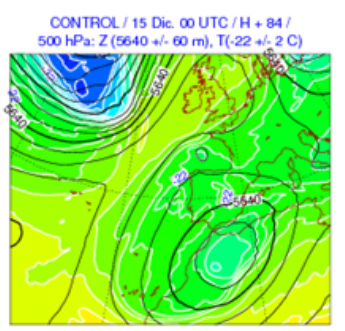

CONTROL/ 15 Dic. $00 \mathrm{UTC} / \mathrm{H}+8 \mathrm{~B} / \mathrm{f}$

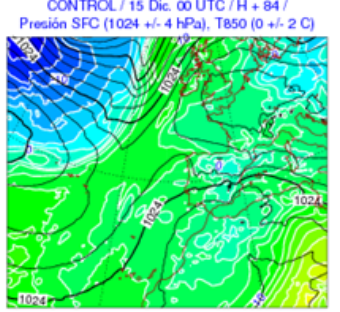

CONTROL/ 15 Dic, $\infty$ UTC / $/ \mathrm{H}+84 /$
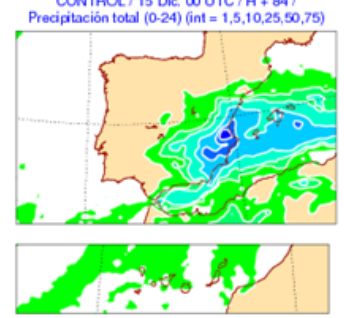

SUPERGRUPOS // 15 Dic. $00 Z / H+84$ / 18 Dic. 2016, Domingo, a $12 Z$

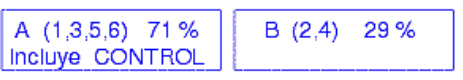

500 hPa: Z $(5640+/-60 \mathrm{~m}), \mathrm{T}(-22+/-2 \mathrm{C})$

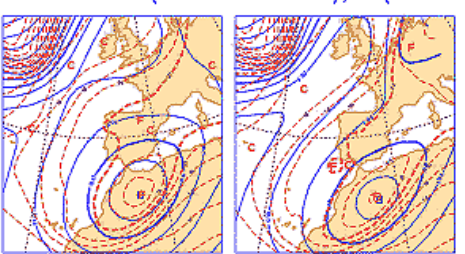

Presion en SFC $(1024+/-4$ hPa), T en $850(0+/-2 \mathrm{C})$

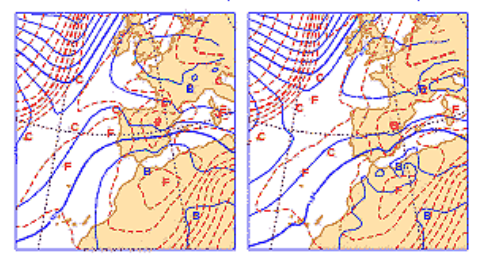

Prob. de Prec. (0-24) sup. a $1 \mathrm{~mm}$, para cada supergrupo;(int $=10,40,70,90 \%)$
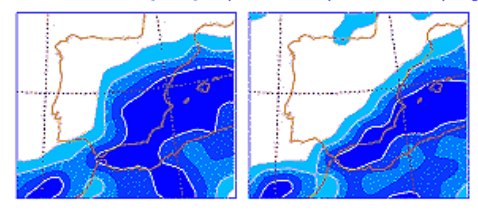

Figura 51.20: ECHRES y Control para D+7 (izquierda). Grupos para D+7 (derecha). 


\subsubsection{Episodio A: mapas de probabilidad de precipitación en $24 \mathrm{~h}$}

Desde el día 11 a las 12 UTC (D+7) y hasta el 13 a las 12 UTC, los mapas de probabilidad de precipitación en $24 \mathrm{~h}$ (Figura 51.21) muestran una focalización en torno al golfo de Valencia, disminuyendo los valores sobre Cataluña. En las dos pasadas del día 14 (D+4) se observa un desplazamiento de las precipitaciones intensas hacia el mar, tanto por parte de ECHRES como por el ECENS. Este seguidismo del ECENS es un rasgo negativo que afortunadamente sólo permaneció dos pasadas.

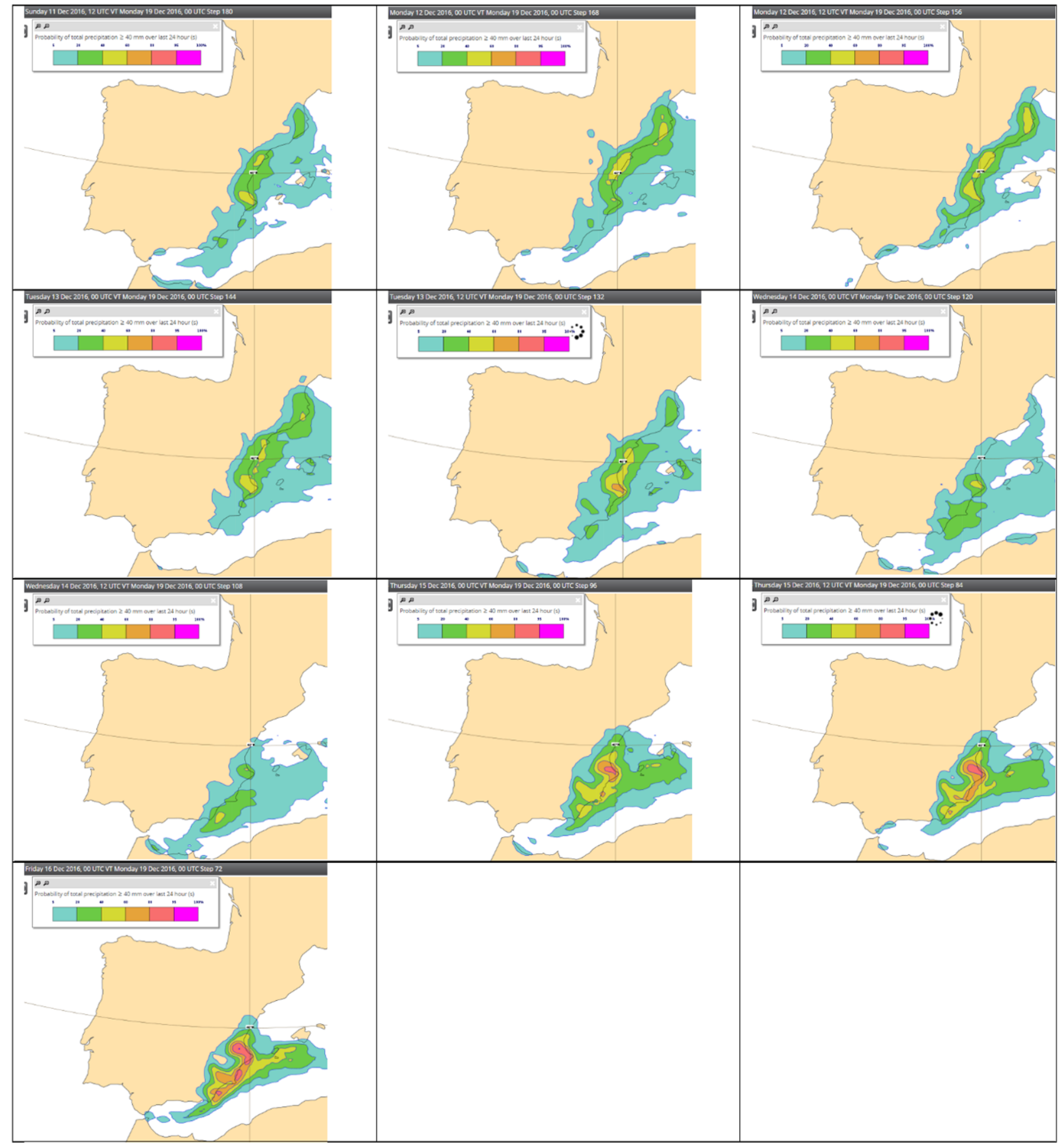

Figura 51.21: Mapas de probabilidad de precipitación mayor que $40 \mathrm{~mm}$ válidos para el día 19 a las 00 UTC, generados cada 12 horas, desde el día 11 a las 12:00 UTC (arriba izquierda) hasta el día 16 a las 00:00 UTC (abajo). 
(Dic-2016 y Mar-2017)

\subsubsection{Episodio A: Extreme Forecast Index (EFI) y Shift Of Tail (SOT)}

Se observan valores muy altos de EFI y SOT (secs. 27.7.2 en la página 420 y 27.7 .3 en la pági- na 421) donde las probabilidades de lluvias intensas son altas (Figura 51.22), lo que indica el alto grado de rareza de unas precipitaciones tan intensas para la época del año.

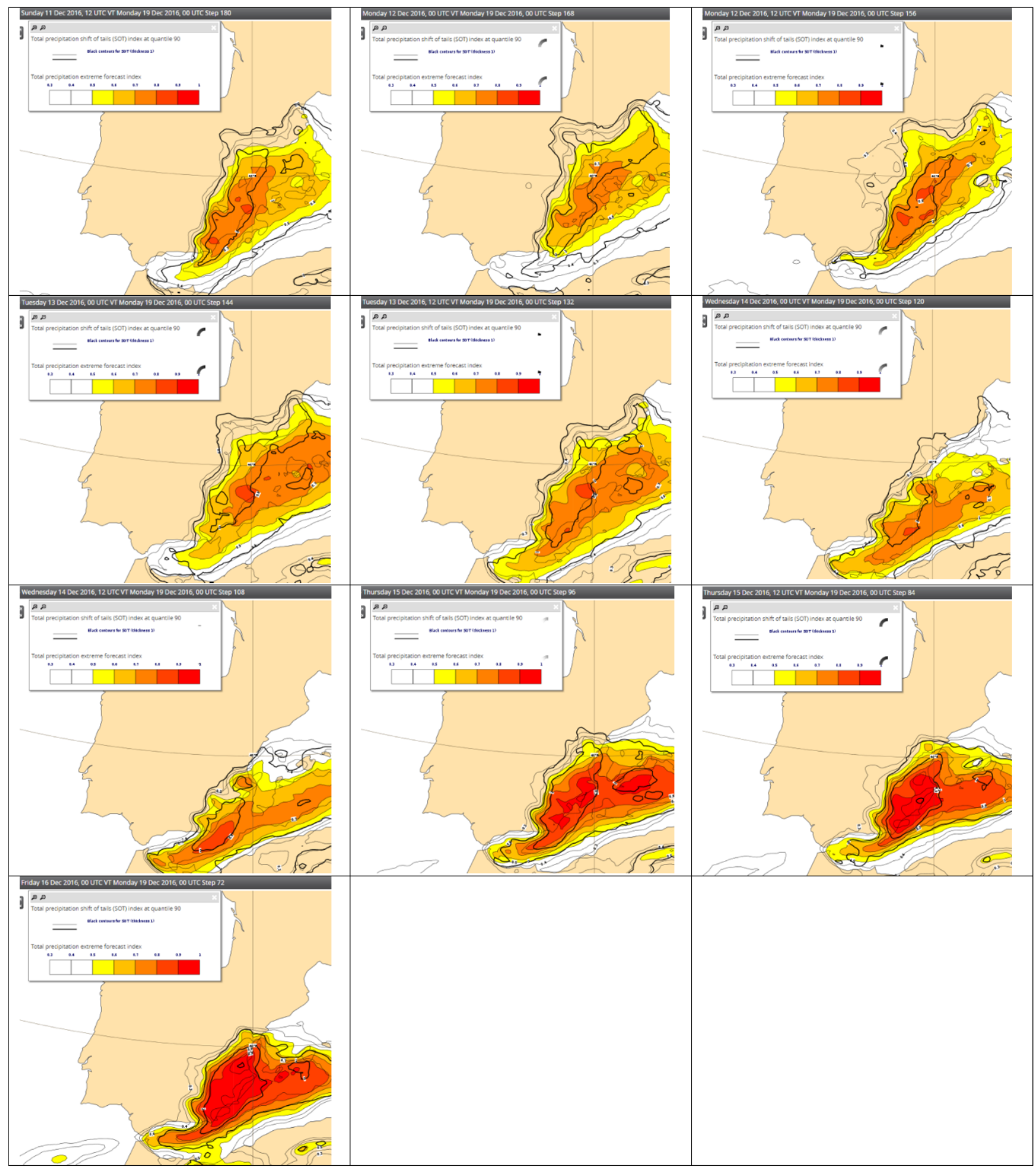

Figura 51.22: Mapas de EFI y SOT de precipitación en 24 horas válidos para el día 19 a las 00 UTC, generados cada 12 horas, desde el día 11 a las 12:00 UTC (arriba izquierda) hasta el día 16 a las 00:00 UTC (abajo). 


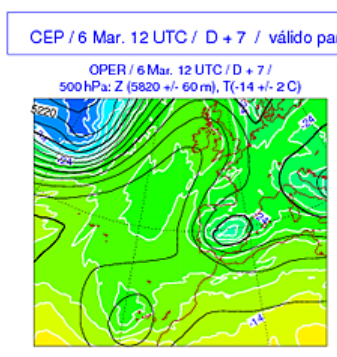

OPER/ 6 Mar. 12 UTC $/ D+7 /$
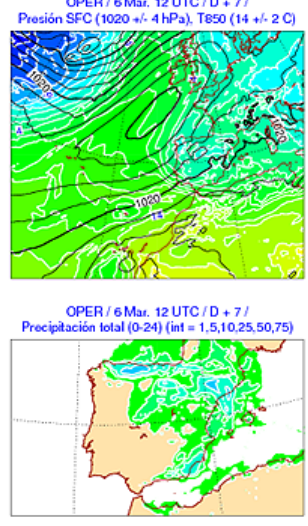

$\because 0_{0} 8$

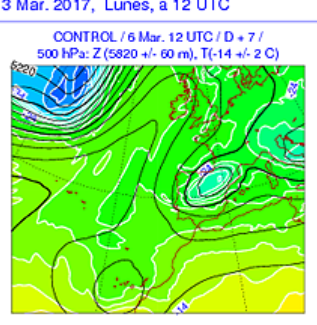

CONTROL/6 Max. 12 UTC/D $+7 /$

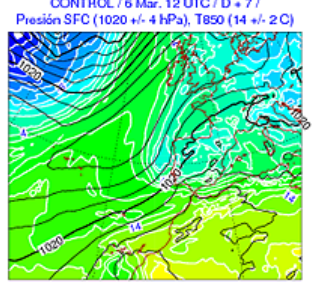

CONTROL / $6 \mathrm{Mar}, 12 \mathrm{UTC} / \mathrm{D}+7 /$

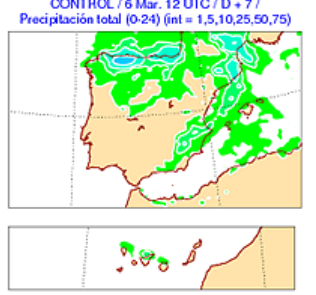

GRUPOS (Z-500) / 6 Mar. / D + 7 / valido para: 13 Mar. 2017, Lunes, a 12 Z Grupo 1: $17 \mathrm{~m}$. Grupo 2: $8 \mathrm{~m}$. Grvpo 3: $8 \mathrm{~m}$. Grupo 4: $7 \mathrm{~m}$. Grup 5: $6 \mathrm{~m}$. Grupo 6: $5 \mathrm{~m}$.

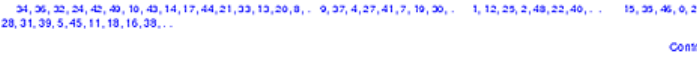
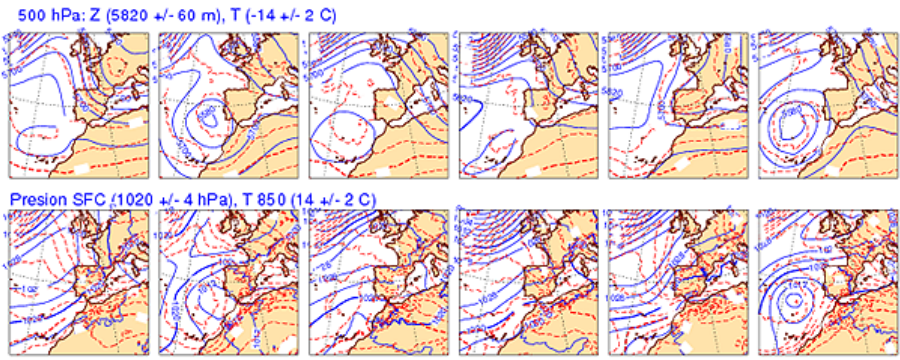

Prob. de prec. tot. (0-24) superior a $1 \mathrm{~mm}$ para cada grupo; (int $=10,40,70,90 \%$ )

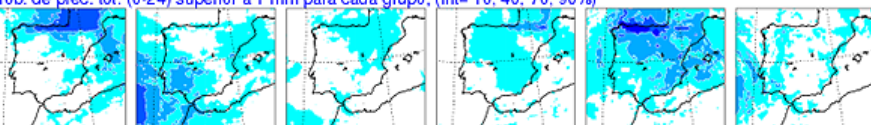

Figura 51.23: Predicción para el día 13-03-2017. Pasada: 06-03-2017 a 12 UTC. ECHRES y control (izquierda) y grupos (derecha).

\subsubsection{Episodio A: predicción operativa y avisos}

La alta predecibilidad de este episodio nos permitió emitir avisos de color naranja por precipitaciones intensas en el D+2; e incluso se podrían haber emitido con mayor antelación.

\subsubsection{Episodio B del 13-03-2017: compa- ración ECHRES y ECENS, escala si- nóptica}

Resulta llamativo que ni el ECHRES ni el ECENS predijeran ningún escenario similar al que realmente ocurrió hasta el día 6 a las 12 UTC (Figura 51.23), cuando por primera vez el ECHRES y el $12 \%$ del ECENS muestran un escenario de lluvias intensas en el Mediterráneo.
En las siguientes pasadas las probabilidades de escenarios asociados a lluvias intensas en el Mediterráneo occidental (prob-1) crecen de forma consistente. Sin embargo, si nos limitamos al área mediterránea peninsular (nuestro interés), la evolución de las probabilidades (prob-2) es desigual hasta 4.5 días antes (Tabla 51.2).

Llama la atención la fuerte inconsistencia en el D+5 (Figura 51.24 en la página siguiente), pues ningún escenario era similar al análisis. En el gráfico de los "espaguetis" se intuye que ninguno o casi ninguno es compatible con un viento del E o NE sobre el este y sureste peninsular.

A partir del día 9 la dispersión disminuye de forma consistente y podemos hablar de una situación más predecible.

\begin{tabular}{|l|c|c|c|c|c|c|c|}
\hline \hline Pasada: & $\begin{array}{c}6 / 3 / 2017 \\
\text { a 12 UTC } \\
\mathrm{D}+7\end{array}$ & $\begin{array}{c}7 / 3 / 2017 \\
\text { a 00 UTC } \\
\mathrm{D}+6.5\end{array}$ & $\begin{array}{c}7 / 3 / 2017 \\
\text { a } 12 \text { UTC } \\
\mathrm{D}+6\end{array}$ & $\begin{array}{c}8 / 3 / 2017 \\
\text { a 00 UTC } \\
\mathrm{D}+5.5\end{array}$ & $\begin{array}{c}8 / 3 / 2017 \\
\text { a } 12 \text { UTC } \\
\mathrm{D}+5\end{array}$ & $\begin{array}{c}9 / 3 / 2017 \\
\text { a } 00 \text { UTC } \\
\mathrm{D}+4.5\end{array}$ & $\begin{array}{c}9 / 3 / 2017 \\
\text { a } 12 \text { UTC } \\
\mathrm{D}+4\end{array}$ \\
\hline \hline Prob-1 & $12 \%$ & $26 \%$ & $28 \%$ & $42 \%$ & $44 \%$ & $100 \%$ & $100 \%$ \\
\hline Prob-2 & $12 \%$ & $14 \%$ & $6 \%$ & $14 \%$ & $0 \%$ & $46 \%$ & $86 \%$ \\
\hline \hline
\end{tabular}

Tabla 51.2: Evolución de las probabilidades de escenarios adversos en el Mediterráneo occidental (prob-1) y área mediterránea peninsular (prob-2). 


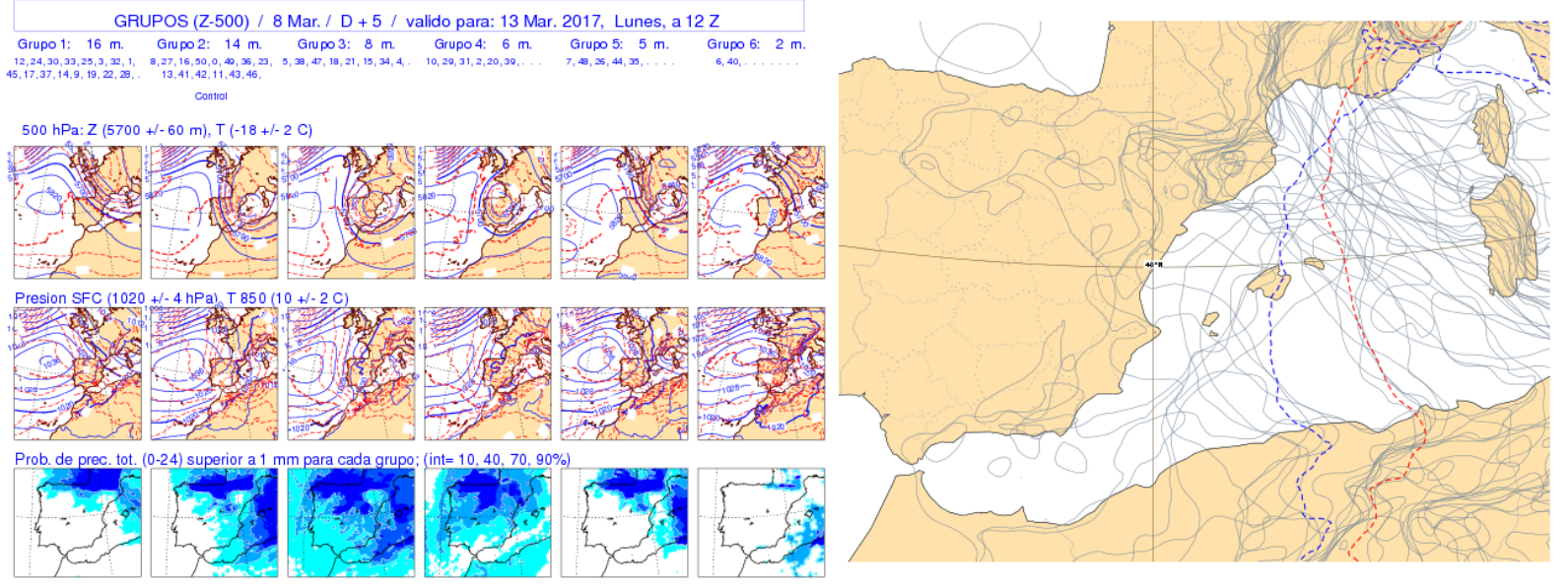

Figura 51.24: D+5: grupos (izquierda); espaguetis de presión, isolínea de 1014 hPa. ECHRES: línea azul a trazos. Control: línea roja a trazos. ECENS: líneas grises (derecha)

\subsubsection{Episodio B: predicción de la baja mesoescalar. ECHRES y ECENS}

La Figura 51.25 nos muestra la posición de la baja y la precipitación en 24 horas prevista para el día 13 a las 12 UTC, en las pasadas sucesivas desde el 9 a las 12 UTC hasta el 10 a las 12 UTC, cada 12 horas. El viento en superficie focaliza las precipitaciones inten- sas; conforme la baja se va situando más próxima al SE peninsular mayor es la componente este del viento $\mathrm{y}$, por consiguiente, mayor la humedad aportada y las precipitaciones. El tamaño de la baja es pequeño (diámetro de centenares de $\mathrm{km}$ ), típico de la mesoescala y, por ello, su predicción suele ser bastante incierta. Se observa como ECHRES es inconsistente en estas pasadas.

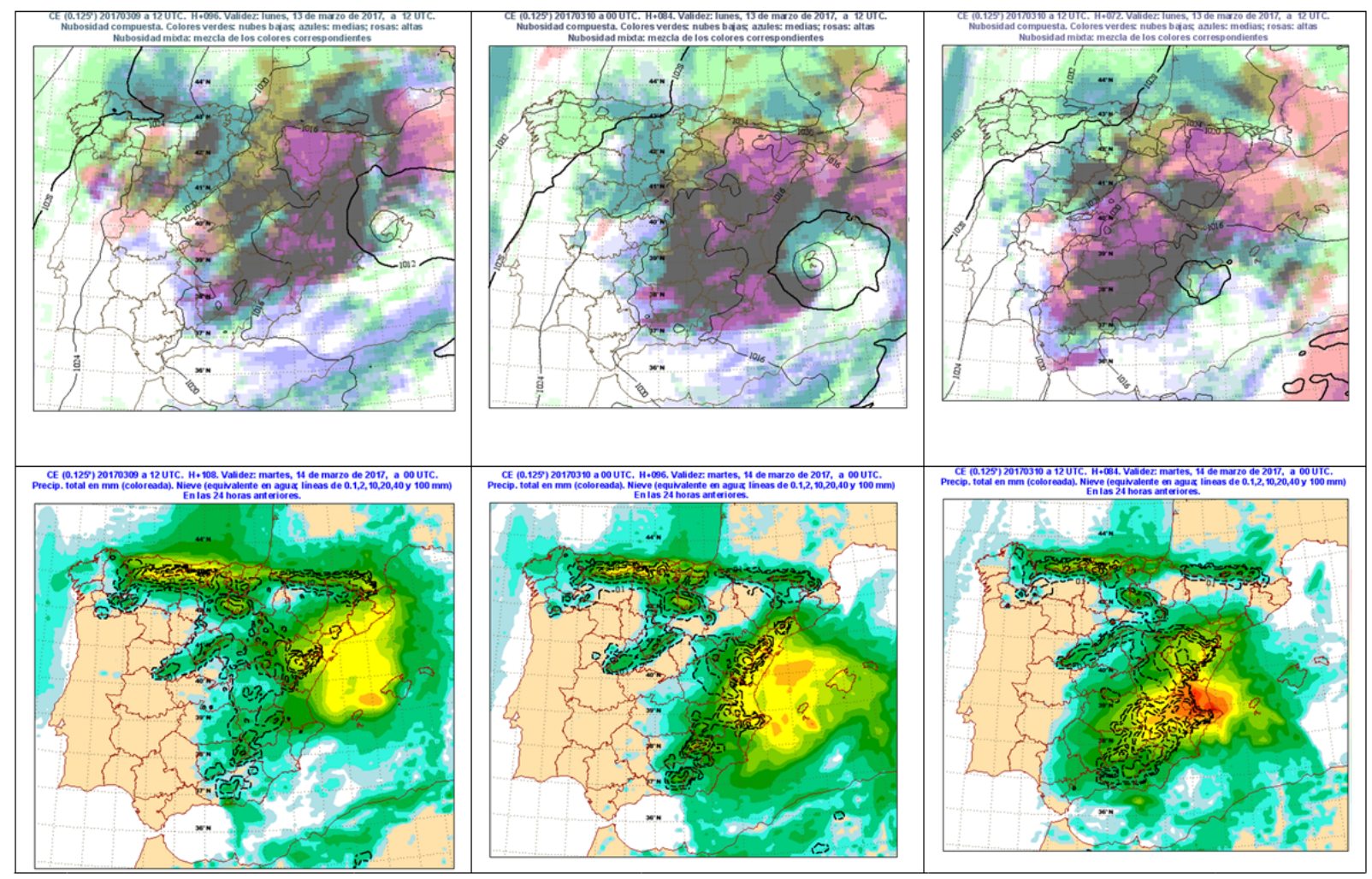

Figura 51.25: Predicción del campo de presión a nivel del mar y nubosidad del 10-03-2017 a las 00 UTC (arriba), y del 10-03-2017 a las 12 UTC, precipitación y nieve en 24 horas (abajo) para el 13-03-2017 del ECHRES. 


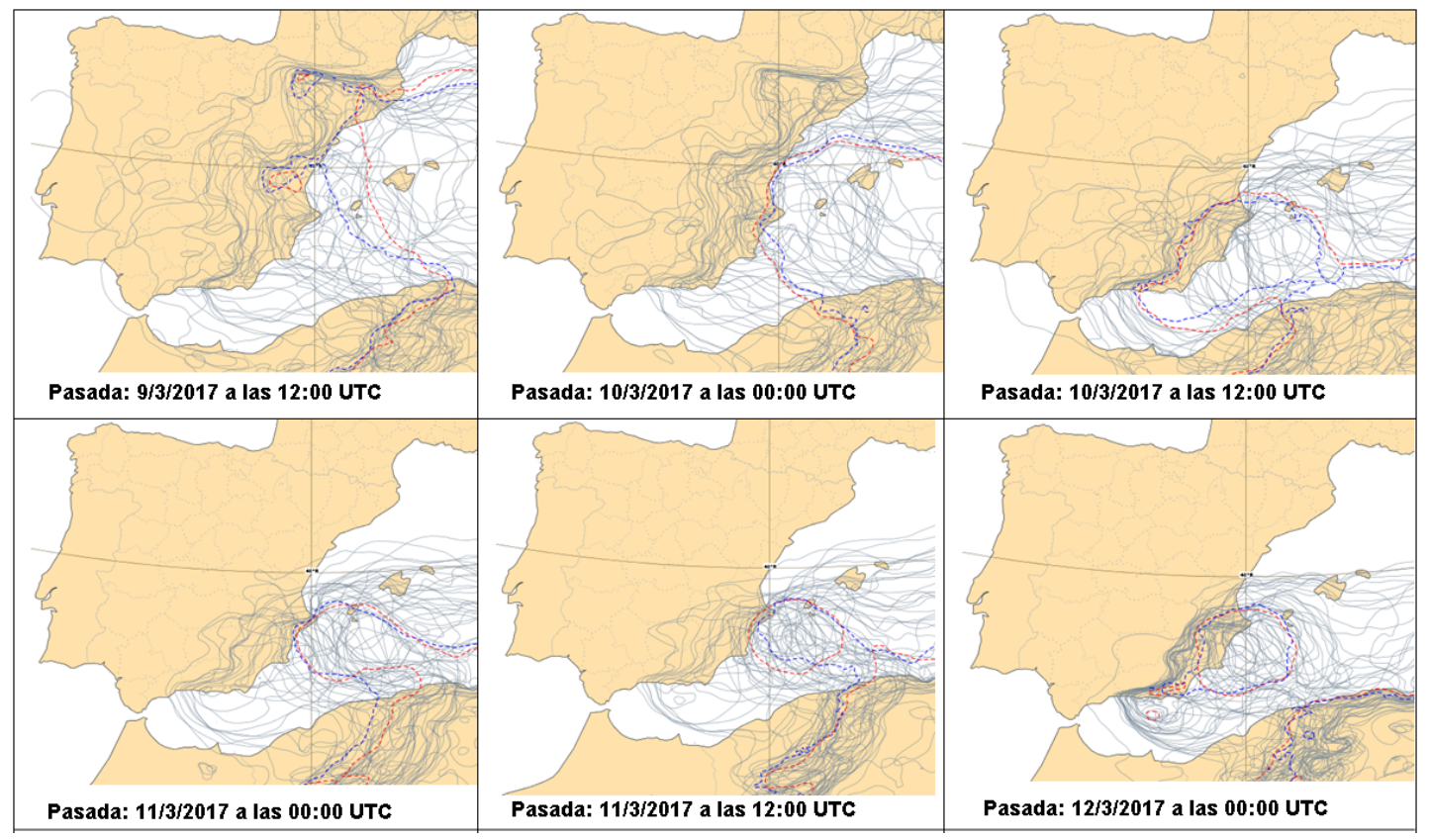

Figura 51.26: Espaguetis del campo de presión al nivel del mar, ECHRES y ECENS, verificando el 13-03-2017, pasadas cada 12 horas desde el 09-03-2017 a las 12 UTC (arriba izquierda) hasta el 12-03-2017 a las 00 UTC (abajo derecha). Isolínea de 1014 hPa. ECHRES: línea azul a trazos. Control: línea roja a trazos. ECENS: líneas grises.

Para analizar el comportamiento del ECENS en la predicción de la baja mesoescalar, más útil que los campos medios de la presión de los miembros de cada grupo son los espaguetis (Figura 51.26). De esta forma estamos viendo de forma explícita todos los miembros junto con ECHRES.
El uso de la media del ECENS y su dispersión es otra forma de evaluar la incertidumbre de la posición de la baja (Figura 51.27). De cualquier forma, podemos concluir que solo a partir de la pasada del 10 a las 12 UTC, la dispersión comenzó a reducirse y, por ello, a aumentar la predecibilidad.

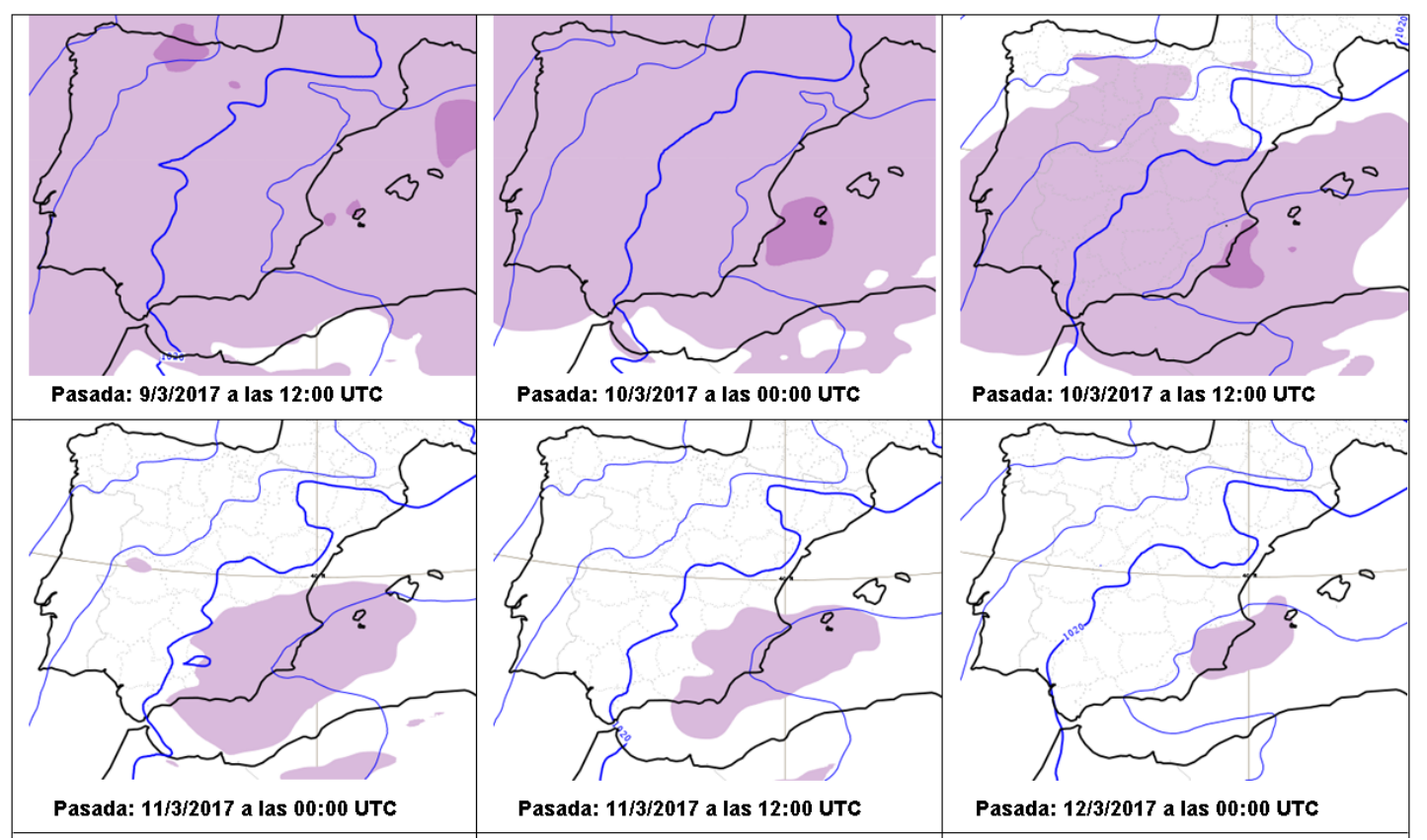

Figura 51.27: Media del campo de presión al nivel del mar del ECENS y su dispersión (sombreado), verificando el 13-03-2017, pasadas cada 12 horas desde el 09-03-2017 a las 12 UTC (arriba izquierda) hasta el 12-03-2017 a las OO UTC (abajo derecha). 


\subsubsection{Episodio B: mapas de probabilidad,} EFI y SOT

Los mapas de probabilidad de precipitación (Figura 51.28), EFI y SOT (Figura 51.29) son concordantes, mostrando altos valores de EFI y SOT cuando las probabilidades de lluvias intensas son también altas. De nuevo se observa como la pasada del 10 a las 12 UTC es la primera que muestra una predecibilidad alta.

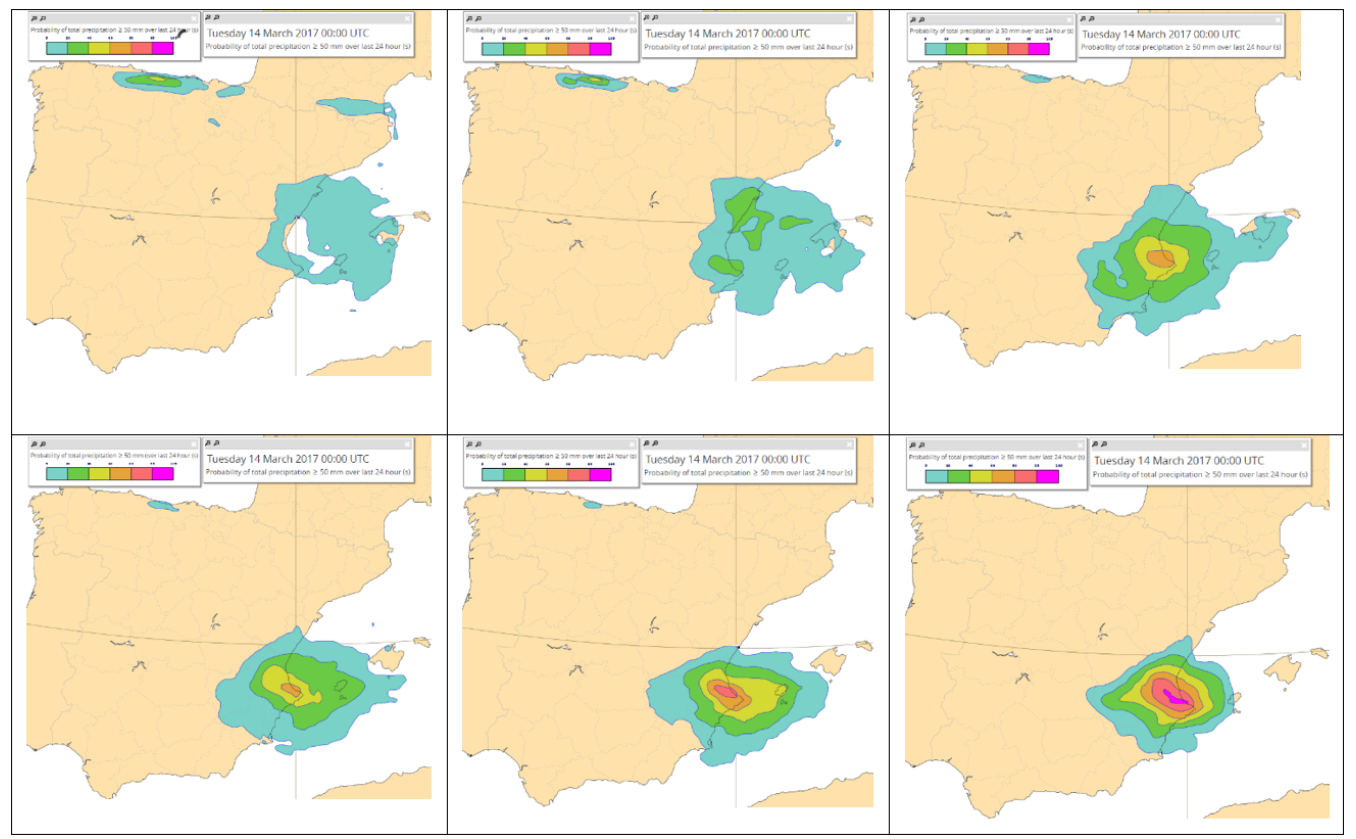

Figura 51.28: Probabilidades de pcp > 50 mm/24 horas, verificando el 13-03-2017, pasadas cada 12 horas desde el 09-03-2017 a las 12 UTC (arriba izquierda) hasta el 12-03-2017 a las 00 UTC (abajo derecha).

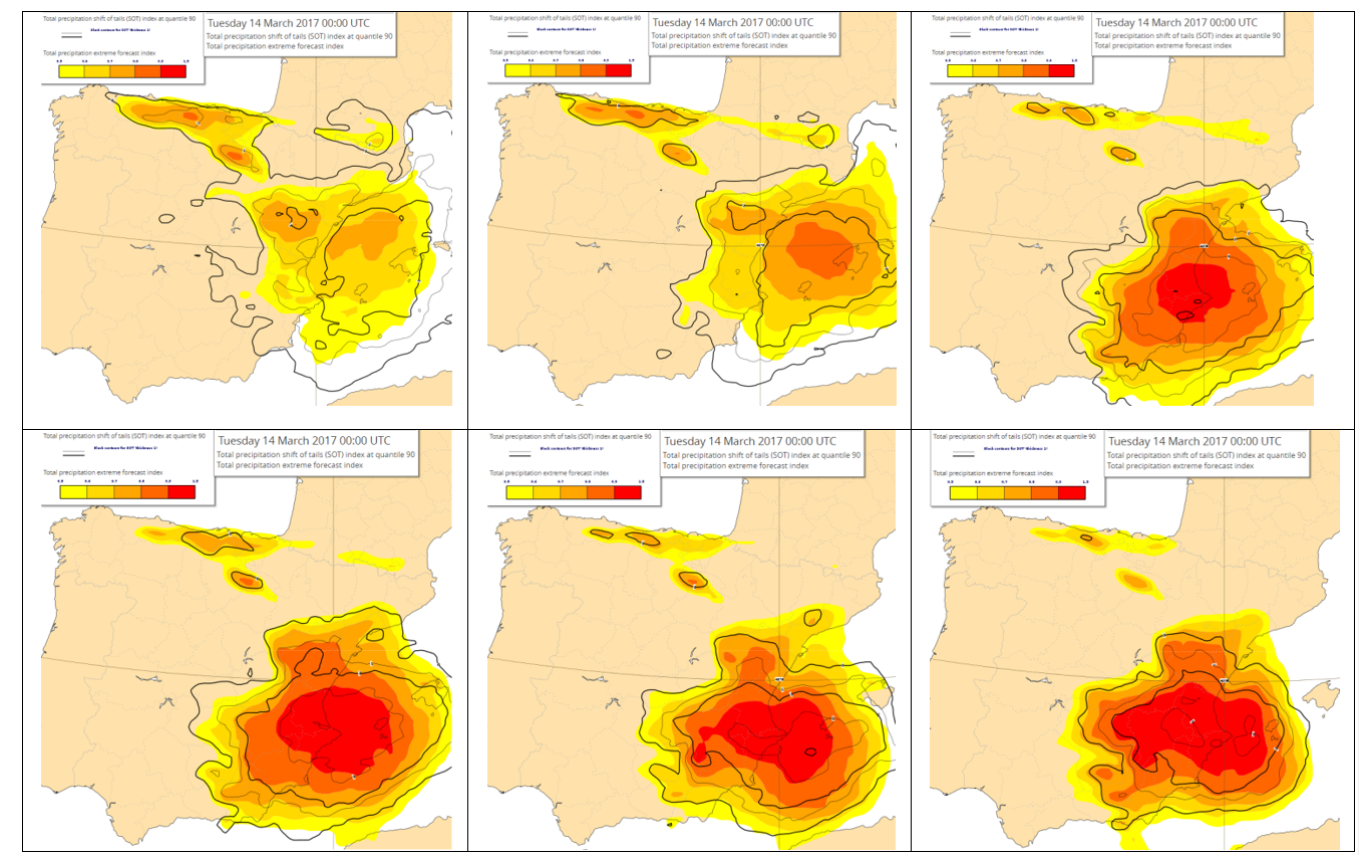

Figura 51.29: EFI y SOT de precipitación en 24 h, verificando el 13-03-2017, pasadas cada 12 horas desde el 09-03-2017 a las 12 UTC (arriba izquierda) hasta el 12-03-2017 a las 00 UTC (abajo derecha). 


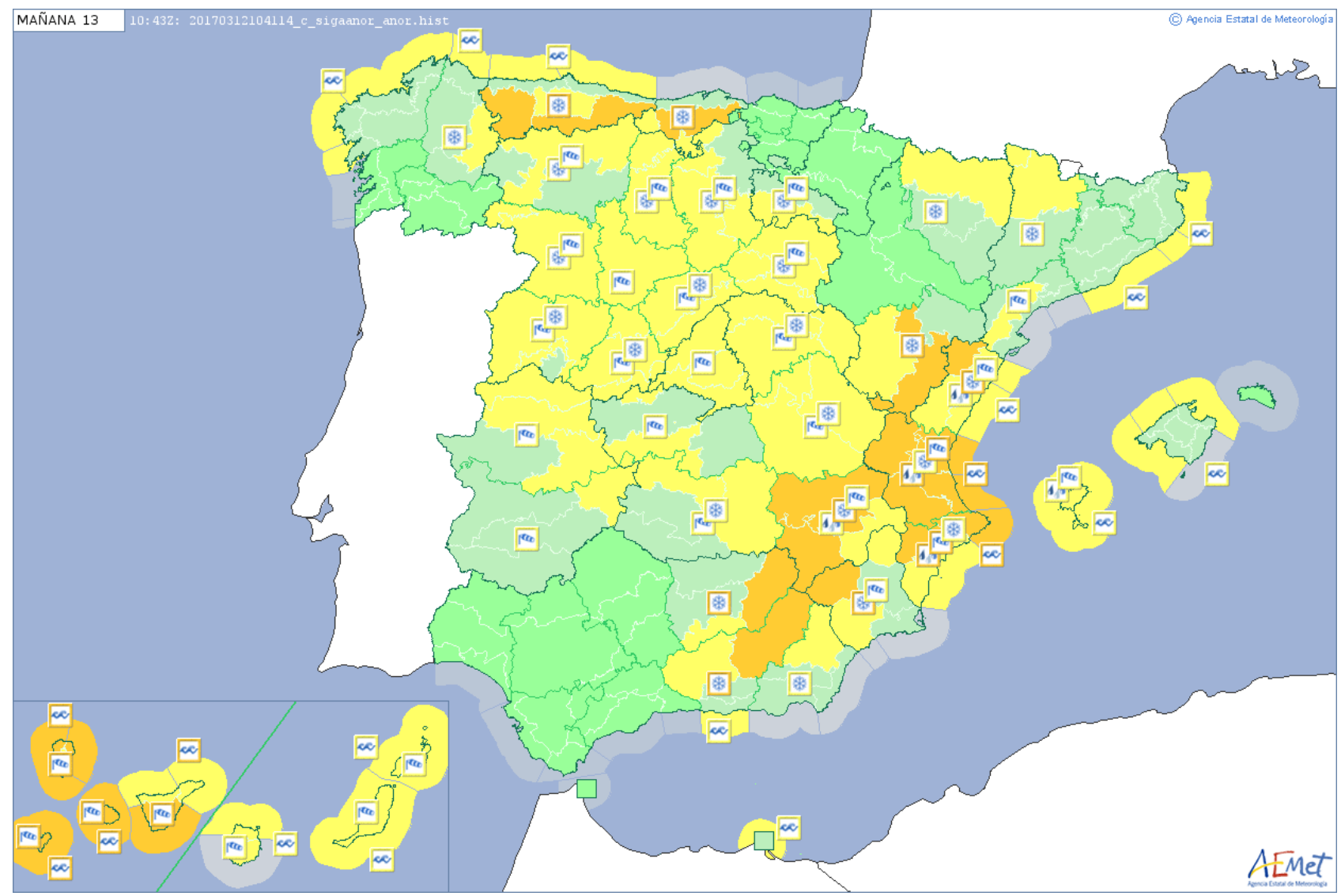

Figura 51.30: Avisos previstos el día 12-03-2017 para el 13-03-2017 (D+1).

\subsubsection{Episodio B: predicción operativa y avisos}

Teniendo en cuenta que el ECENS con la pasada del día 10 a las 12 UTC no está disponible hasta la madrugada del día 11 y que era adecuado comparar con las siguientes pasadas para contrastar la información, los avisos de color naranja en las zonas del litoral sur de la provincia de Valencia y norte de Alicante no se emitieron, con una probabilidad media, hasta el día 12 (D+1). El fuerte gradiente de probabilidad de precipitación justifica los avisos naranjas en dichas zonas y la ausencia de los mismos al sur. Dichos avisos se podrían haber difundido antes pero con una baja probabilidad.

\subsection{Conclusiones}

Los fenómenos observados de los dos episodios analizados son muy similares, sobre todo en intensidad y acumulación de la precipitación y, sin embargo, su predecibilidad es bastante diferente. El episodio A comienza a ser previsto a $\mathrm{D}+10 \mathrm{y}$, en sucesivas pasadas, de forma consistente y con probabilidades crecientes, de forma que para D+7 y rangos más cortos la dispersión es mínima, pues sólo hay un escenario.
En el mapa de avisos (Figura 51.30) se puede observar como en el litoral sur de Alicante (donde se encuentra la ciudad de Alicante, una zona de las zonas más afectadas como se ha mencionado anteriormente) el aviso es amarillo; la mañana del día 12 se emitió aviso P1 $(30 \mathrm{~mm} / \mathrm{h})$ de $0 \mathrm{~h}$ a $15 \mathrm{~h}$ del día 13 ; y, por la noche, con las nuevas pasadas de los modelos, se alargó a todo el día 13 y se dio también de $\mathrm{P} 2(80 \mathrm{~mm} / 12$ horas). El día 13 por la mañana las inconsistencias entre ECHRES y HARMONIE-AROME (sec. 20.4 en la página 310) propiciaron rebajar los umbrales del amarillo de precipitación (a $20 \mathrm{~mm} / \mathrm{h}$ y $60 \mathrm{~mm} / 12$ h). Para esta zona no se llegó a emitir el aviso naranja, ni siquiera observado. En este caso el ECHRES tuvo un mejor comportamiento que HARMONIE-AROME.

Sin embargo, para el episodio B el comportamiento de los modelos es muy diferente, pues aunque empieza a preverse a D+7, en las sucesivas pasadas los modelos son inconsistentes, especialmente ECENS que a D+5 no muestra ningún escenario compatible con las lluvias intensas. Las causas están asociadas a las diferentes estructuras meteorológicas responsables del viento húmedo de levante sobre el este y sureste peninsular. Mientras para el episodio A se trata de grandes estructuras de presión (anticiclón en el conti- 
nente europeo y borrasca en el norte de África), para el episodio B la baja mesoescalar en el entorno del Mediterráneo occidental es clave para la focalización de las precipitaciones.

La consecuencia más importante, en predicción operativa, de la escasa predecibilidad es la dificultad en la emisión de avisos de fenómenos adversos. El episodio B sólo fue avisado con un nivel naranja a D+1 con una probabilidad media (exceptuando el litoral sur de Alicante donde hubo una clara subpredicción) mientras que el episodio A pudo serlo a $\mathrm{D}+3 / \mathrm{D}+2$ con un nivel alto de probabilidad. La probabilidad es la variable que cuantifica la incertidumbre de la predicción y, con mucha frecuencia, los fenómenos adversos están asociados a probabilidades bajas, como el episodio B. Hay una costumbre bastante generalizada en AEMET de no emitir avisos con probabilidades bajas y de esperar a que los fenómenos tengan mayor probabilidad para hacerlo. Este tipo de criterios debería revisarse en el futuro.

Se observan valores altos de EFI y SOT cuando las probabilidades de precipitaciones intensas son también altas. En los dos episodios hay una relación entre los mencionados valores y la adversidad de la situación pero hemos de tener en cuenta que no siempre es así y que es necesario interpretar el EFI y SOT como lo que son, índices de rareza y no, necesariamente, de adversidad.

La Figura 51.31 muestra imágenes de algunos de los impactos del episodio de diciembre de 2016.
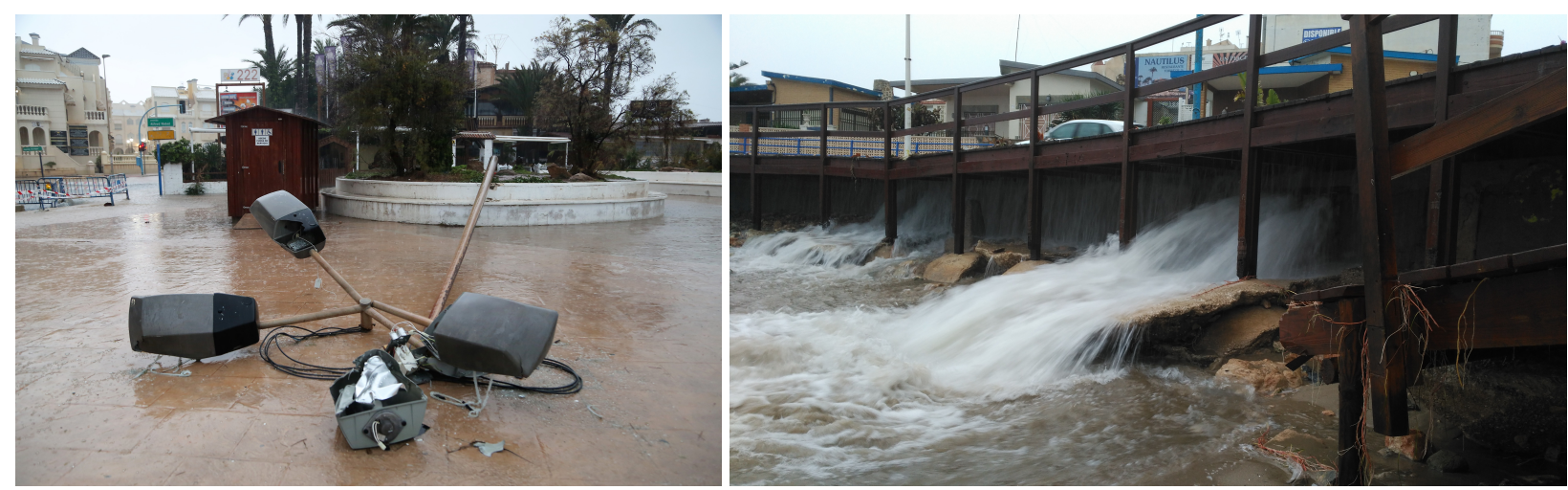

Figura 51.31: Impactos producidos por el episodio de diciembre de 2016 (día 18) en Torrevieja, fotografías de JOAQUÍN CARRIÓN (izquierda) y RICARDO GRANADOS (derecha), cedidas a través de Proyecto Mastral Torrevieja http: //www. eltiempoentorrevieja. es/. 


\subsection{Referencias}

[1] PERSSON, Anders. "User guide to ECMWF forecast products". En: Ecmwf March (2011), página 127 (citado en página 785). 